\title{
A Simulation-Based Dynamic Programming Method for Interchange Scheduling of Port Collecting and Distributing Network
}

\author{
Yun Peng $\mathbb{D},{ }^{1}$ Wenyuan Wang $\mathbb{D},{ }^{1}$ Xinglu Xu $\mathbb{D},{ }^{1}$ Modi Chen $\mathbb{D},{ }^{2}$ \\ Xiangqun Song ${ }^{D}{ }^{1}$ and Xiangda $\mathrm{Li}$ iD ${ }^{1}$ \\ ${ }^{1}$ State Key Laboratory of Coastal and Offshore Engineering, Dalian University of Technology, No. 2 Linggong Road, Ganjingzi District, \\ Dalian, Liaoning 116023, China \\ ${ }^{2}$ CCCC-FHDI Engineering Co., Ltd., Guangzhou, China
}

Correspondence should be addressed to Wenyuan Wang; wangwenyuan@dlut.edu.cn

Received 11 February 2018; Revised 5 July 2018; Accepted 19 July 2018; Published 6 August 2018

Academic Editor: Emanuele Crisostomi

Copyright $\odot 2018$ Yun Peng et al. This is an open access article distributed under the Creative Commons Attribution License, which permits unrestricted use, distribution, and reproduction in any medium, provided the original work is properly cited.

\begin{abstract}
As one of the effective methods to reduce congestion, grade intersection has already been changed to interchange in port collecting and distributing network (PCDN) of many Chinese ports, since the first interchange was built in the PCDN of Dalian port in 1924. Due to the growing demand for port freight transportation, congestion in PCDN is becoming one of the inevitable problems that need to be solved. This paper addresses the best interchange scheduling multistage decision problem in PCDN at a network level. The main challenges are how to estimate the delay time and cope with high uncertainties in port network and PCDN. Therefore, a simulation-based dynamic programming (DP) model is proposed with the purpose of minimizing total cost in lifetime period by combining a DP model and two nested simulation models together. Two simulation models are built to figure out the delay cost in the optimization model, which cannot be calculated by mathematical analysis due to complex vehicle travel patterns and irregular traffic volume caused by random events, such as the arrival pattern of ships', natural conditions, and storage period of cargos. Finally, a real project in northern China is presented as a case study. The proposed method can be applied in similar cases and can help solve analogous complicated multistage problems.
\end{abstract}

\section{Introduction}

According to the statistics of United Nations Conference on Trade and Development (UNCTAD) 2016, 89.9\% of the world trade volume is transported by vessels. Ports are still important hubs in the logistic chain of transportation sector. Port collecting and distributing network (PCDN), which connects ports and urban transport systems, is influenced by both the port freight transportation and urban passenger traffic. Due to the growing demand for port freight transportation, congestion in PCDN is becoming one of the inevitable problems that need to be solved.

Our research is based on a real case; local governments are going to change some intersections to interchanges during the PCDN's lifetime period, as the interchange reconstruction can effectively reduce congestion. It is very essential for decision makers to obtain the best interchange construction time for each node in PCDN: When and which intersection should be reconstruction so that the total cost, including construction cost and delay cost, is minimized? The particularity and complexity of this multistage dynamic programming (DP) problem rest on the traffic volume in PCDN network which is not steady and periodic. To the best of our knowledge, few studies have tried to do that so far, due to the particularity features of this kind of problem.

DP model has always been used in this kind of multistage decision problem since it was proposed by Bellman [1]. The equipment replacement optimization is one of the representative research fields. Waddell [2] did a research based on a case study from Phillips Petro Company to optimize 
the replacement decisions for individual highway tractors. Hartman [3] took the replacement of equipment with net present value analysis into consideration. Moghaddam and Usher [4] proposed a mathematical model on preventive maintenance schedules for a system of components with increasing rate of failure. This model was solved by branchand-bound method. Bacalhau et al. [5] built an optimization model which was constrained by the system reliability to optimize the preventive maintenance. This model aims to find the best relationship between system reliability and the allocation of maintenance resources and was solved by a reduced DP approach. Aversa and Shapiro [6] took the maintenance and rebuild costs, tax depreciation, and other costs into consideration and used a dynamic programming model to decide when to maintain, rebuild, or replace aging machines, respectively. Fan et al. [7] has done a series of studies on equipment replacement problem and put forward a developed DP method which is general.

However, individual interchange nodes in PCDN are not independent of each other. When an intersection is being changed to an interchange, it is impassable for vehicles during this period of time. Even a small change may have a significant impact in PCDN, which may cause vehicles to change their travelling routes to meet the demands of time and cargo transport. The problem proposed in this paper must be solved at a network level compared to project level.

Many researchers have studied the network retrofit problem in respect of highways, bridges, supply chains, etc. in the field of transportation engineering. Network theories are widely used in the retrofit problem of critical infrastructure. For example, Liu et al. [8] focused on the problem of optimizing limited retrofit resources over multiple highway bridges to improve the resilience and robustness of the entire transportation system in question. Fan et al. [9] applied network theories and system optimization approaches to address highway network problem under seismic hazards, and a two-stage stochastic programming model is used to optimize retrofit decision so that damage caused by future earthquakes will be minimized. Gan and $\mathrm{Xu}$ [10] proposed a fuzzy random multiobjective bilevel programming model to formulate the problem of hedging against seismic risk with the objectives of retrofit costs and the benefits on two separate levels. Dong et al. [11] conducted a research on sustainabilitybased seismic optimization of bridge networks and took the cost and benefit of retrofit interventions into consideration to reduce the earthquake damage to the society, economy, and environment.

It seems the network theories, together with the DP approach, can help solve the proposed interchange nodes construction scheduling problem. Nevertheless, the differences between PCDN and other infrastructure networks must be considered. The key difference lies in the superposition of traffic volume, which is caused by both port freight transportation and urban passenger traffic. Due to the random arrival of ships and complicated operation system of ports, it is hard to formulate the port freight transportation with the increasing of port throughput. Such issue has not been currently considered in network-level DP problems.
The traffic volume in PCDN, which is not steady and periodic, is different from the traffic flow in urban road network. The majority of the research on traffic problem in PCDN pays attention to the congestion problem caused by trucks in port's gates. Guan and Liu [12] used a multiserver queuing model to analyze the gate congestion problem and calculate the waiting cost of trucks. Chen et al. [13] proposed a vessel-dependent-time-windows method to control truck arrivals. As for the relationship between the urban area and port traffic, it is hard to do quantitative research. Pope et al. [14] demonstrated a Q-GERT model for the impact of road traffic flows on ports located in highly congested areas. This model was used to figure out the impact of specific planning changes such as a new interstate highway segment on ports. Cartweight et al. [15] conducted a transportation study for the ports in Long Beach and Los Angeles to find out the port and non-port truck traffic growth. Bin Yu et al. [16] used a system dynamic model to simulate the relationship between land transportation system and economy in the port and analyzed the impact of different transportation levels on the land transportation systems.

Quantification of the delay cost under different scenarios is another challenging task. The scenarios are defined each year by combining different traffic and varied status of nodes (intersections or interchanges) together. Bilbao-Ubillos [17] focused on the recurrent congestion, developed a mathematical formula considering both private costs and social costs, and applied a simulation model to estimate the time lost. Garrido [18] took the Antofagasta in Chile as an example and calculated the congestion cost based on a microsimulation model. Bardal and Jørgensen [19] used a conventional risk model and a time loss model to analyze the delay cost of road accidents and total social costs. It is observed that the delay cost in roads is affected by the traffic volume on each road, the type of road network, the random vehicle run behavior (e.g., car-following and lane-change), etc., which cannot be simply described as a mathematical model as the studies mentioned before. Traffic simulation works as an effective tool in studying road network congestion problem by simulating real-time traffic conditions. For example, Jung et al. [20] used a microsimulation model to examine the safety impact of rainy weather conditions on highways. Burgholzer et al. [21] built a microsimulation model for an intermodal transport network which can simulate the network as well as the traffic participants and individual decisions based on the real data, and the delay time was output to identify critical sections and critical networks. Liu et al. [22] used VISSIM software to simulate U-turn movements at unsignalized intersections and took the behavioral features into consideration, such as the priority rule, lane selection. Dong et al. [23] proposed a city-wide traffic model to simulate the management and intelligent control in traffic network to identify significant links of road network.

The aforementioned works on network retrofit problems mostly focus on highways or bridges; the complexity and particularity of PCDN have not yet been considered. The key difference between PCDN and other infrastructure lies in the superposition of traffic volume, which is caused by both port freight transportation and urban passenger traffic. 


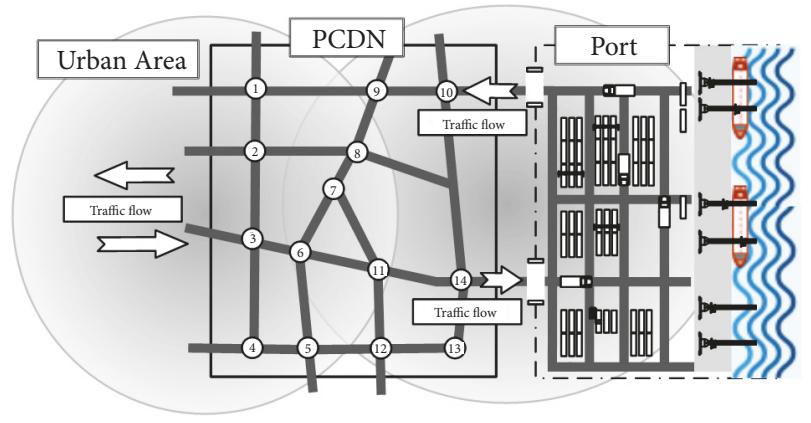

FIGURE 1: The relationship between PCDN, and ports and urban area.

A tremendous amount of the past study on PCDN pays attention to the congestion problem caused by drayage trucks in port's gate system, while urban traffic also impacts PCDN. Due to the random arrival of ships and complicated operation system of ports, it is hard to formulate the port freight transportation with the increasing of port throughput. To solve this, we build a simulation model based on a real project to calculate the traffic volume of drayage trucks from ports. Besides, the four-stage method is used to forecast the urban traffic volume. Then, the DP model is built to solve the multistage decision problem.

This paper will show how PCDN simulation model can be integrated with DP techniques to produce effective interchange schedule decisions from a network-level viewpoint. We aim to develop a simulation-based DP mathematical model for interchange node construction scheduling (INCS) problem while considering random traffic volumes and complex car behavior. Our research approach on how to consider the random traffic volume from ports and urban areas comprehensively and how to solve the multistage decision problem of large irreversible infrastructure reconstruction with huge cost can be reference to similar projects.

The remainder of this paper is organized as follows. Section 2 describes the INCS problem in more detail, including the network representation, notations, and problem description. Section 3 focuses on the simulation-based DP approach representation. Section 4 carries out a real case study for the PCDN in Dalian, China, followed by conclusions and future discussions in Section 5.

\section{Problem Description and Notations}

PCDN is facing serious congestion problem, due to the competition of port traffic and urban traffic flow on limited resource. As shown in Figure 1, the intersections in PCDN, which are coupling influenced by port and urban traffic, are prone to traffic accidents, vehicle congestion, and other random events. Interchange reconstruction is a good way to improve the through capacity [24]. Generally, there are several intersections in a road network (e.g., 14 intersections exist in PCDN in Figure 1). The decision on which intersection should be changed to an interchange node cannot be made only by the crossing's daily traffic volume, its connectivity to other facilities, or daily congestion time. The interchange construction decision should be made at a network level.

For each node, interchange construction decisions mean whether to change the intersection in PCDN to an interchange or not. The decisions are made under total investment budgets by local governments to minimize the whole cost during lifetime period. With the dynamic change of traffic volume, the INCS problem is a multistage decision making problem.

As described in the previous section, this paper focuses on the best construction time for each node in PCDN. To solve the network-level multistage decision problem, PCDN is denoted as $G(N, A)$, where $N$ represents the node set and $A$ is the arc set. Each node $n_{i}$ in $N$ corresponds to a real intersection in PCDN, while $i \in I$ is the node serial number. We can define any one of the intersections as the first one, as shown in Figure 1. Define $a_{i}$ as the voyage arc from node $n_{i}$ to $n_{i+1}$. For example, in Figure 1, $a_{1}$ is defined as the arc from node $n_{1}$ to $n_{2}$. Let decision variable $X_{n_{i}, t}$ represents the construction condition of node $n_{i}$ at each year $t . X_{n_{i}, t}$ is 1 if an intersection is changed to an interchange and 0 otherwise.

The total cost at each year $t$, including all the construction $\operatorname{cost} C_{n_{i}, t}^{\mathrm{c}}$ of retrofit nodes and delay $\operatorname{cost} C_{n_{i}, t}^{\mathrm{d}}$ of PCDN, is hard to be formulated due to the real-time dynamic changed traffic volume. The traffic volume in PCDN covers three parts: urban passenger traffic, passenger and freight traffic produced by logistics zones in PCDN area, and freight traffic caused by ports. Among them, urban passenger traffic and passenger and freight traffic produced by logistics zones in PCDN area, which are both changed according to the peak hours, can be easily formulated by statistical data from local traffic management department and urban planning and design institutes. However, the real-time dynamic port freight traffic at gates, which is influenced by random arrival ships, natural conditions, storage period of cargos, the number of facilities in port, the layout and size of ports, etc., can hardly be presented by a mathematical formula because of high uncertainties and complexity in port operation system. This paper will introduce a port simulation model to calculate the dynamic freight traffic $Q_{j}(h)$ at the gates of ports, where $j \in J$ is the number of gates and $h$ is the time. Then, the traffic volume produced by $Q_{j}(h)$ in PCDN can be obtained by regarding the gates as origin and destination nodes for PCDN. 


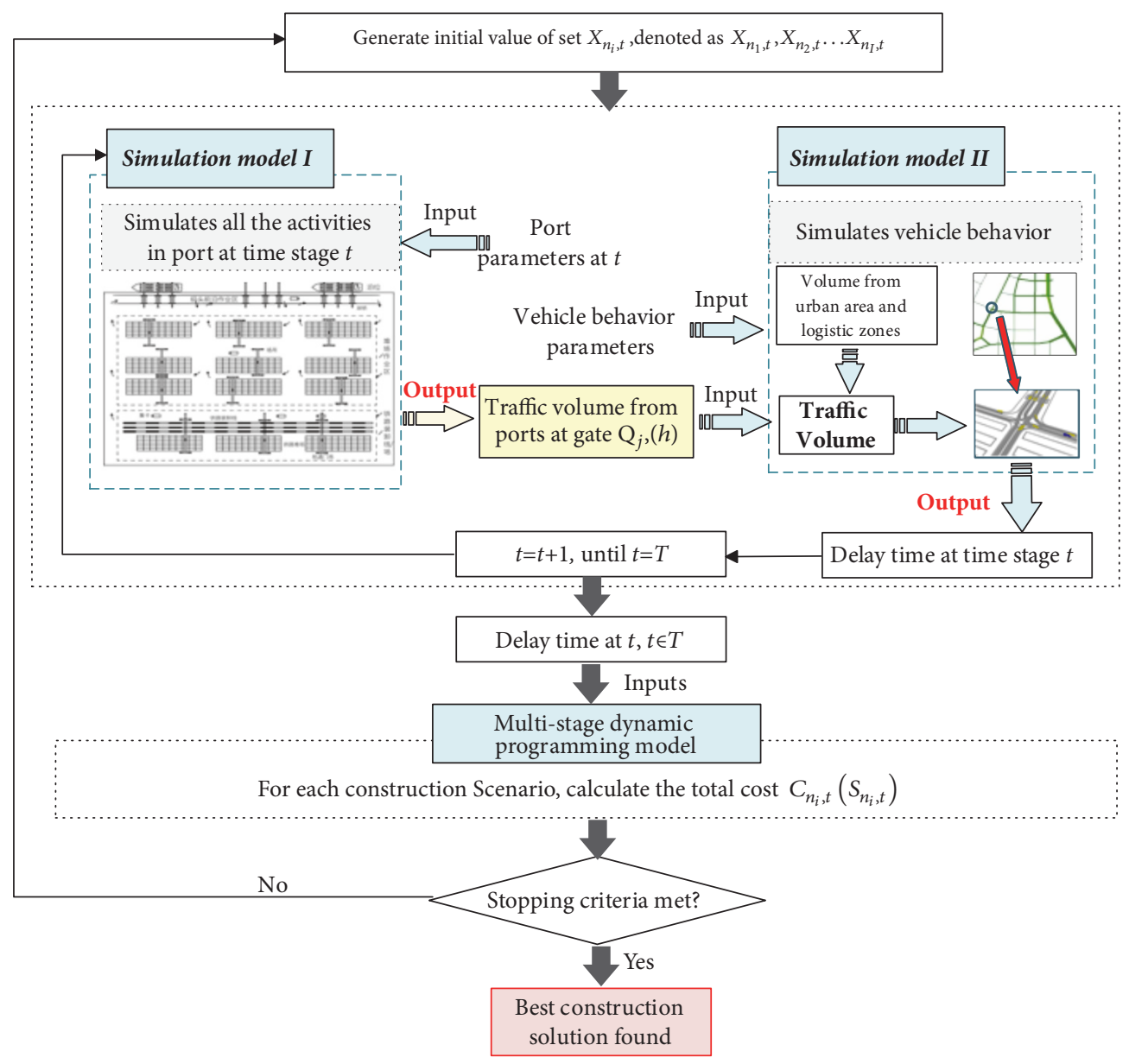

Figure 2: Flowchart of the model framework.

The vehicle routing problem (VRP) for the traffic in PCDN needs to be solved, so that the traffic volume for each node and the delay cost can be calculated. Due to the impact of traffic congestion, drivers' preference, guiding measures, etc. on routing selecting, VRP should be figured out by micro-traffic theories [25]. Therefore, a microscopic traffic simulation model is established with $Q_{j}(h)$ as inputs, which can also be used to compare different traffic conditions between intersections and various types of interchanges. Then, the delay cost for each year $t$ will be obtained by combining the two simulation models together. For the next year $t+1$, the delay cost needs to be recalculated with the change of port throughput and condition of the network.

\section{Methodologies}

3.1. Model Framework. Many complex systems such as manufacturing, supply chain, and container ports are too complex to be modeled analytically. Simulation has been a useful tool for evaluating the performance of such systems. However, instead of finding the best solution, simulation method can only output the data or evaluation index under the given condition. Therefore, the integration of simulation and optimization is needed during this study.

As previously mentioned, there are two main problems with studying the impact and optimizing the cost. The first one is to figure out the traffic volume change with the growth of port throughput. Simulation Model I is built to simulate all the activities in the port area including the arrival of ships, operation process, and truck internal transportation. The output traffic volume of the Simulation Model I will be the input data for microscopic traffic Simulation Model II. Unlike the Simulation Model I, Simulation Model II focuses on the collecting and distributing system outside the port area. These two models are mutually independent. As shown in Figure 2, simulation models would output a set of results and transfer them to the optimization model by data interface. According to the results, the algorithm adjusts the direction of optimal solution searching and creates a new set of feasible solutions. The process would repeat until the stop criterion is satisfied. Sections 3.2 and 3.3 will describe the mathematical model and Simulation Models I and II, respectively.

3.2. DP Model for PCDN. Interchange construction decisions are made by local governments to minimize the whole cost 


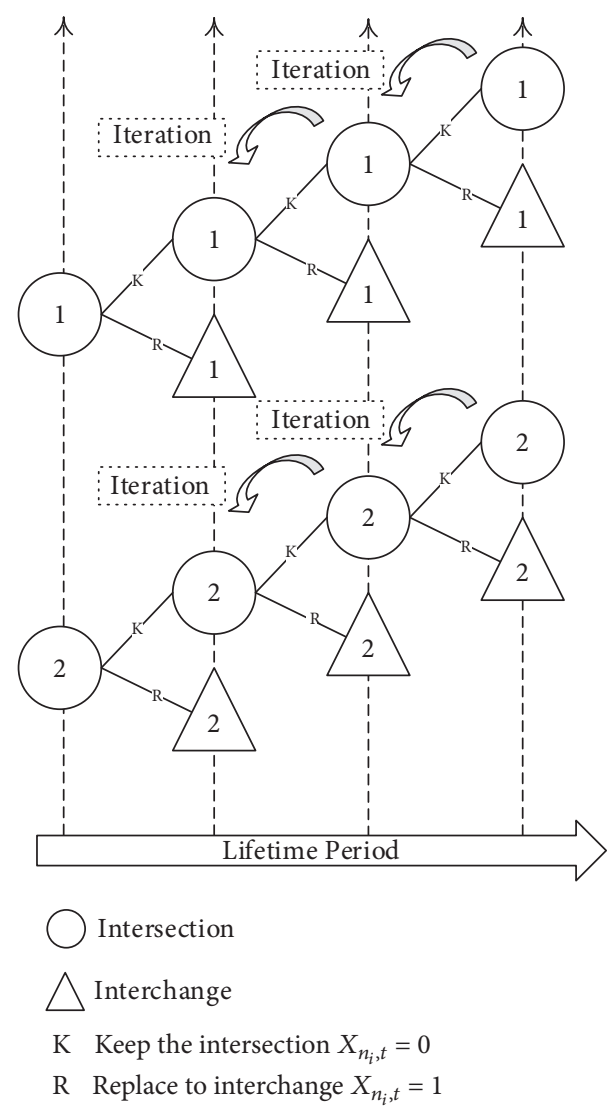

FIGURE 3: Transition graph of a simplified problem.

during a lifetime period. Therefore, a multistage discrete DP model is established.

The DP model is widely used in solving finite-horizon equipment replacement problem. Reverse iteration algorithm, which is used to solve the DP model, is developed by Bellman and follows the principle of optimality. The main idea of this algorithm is to transform $n$ decision variables to a set of $n$ single-variable optimization. Figure 3 illustrates a simplified problem with two intersections and four decision stages. Each arc represents decision either to keep the intersection or replace the intersection with interchange. The "tail" portion must be optimal, so we solve the problem in a backward recursive as shown in the figure, once the subproblem of length $\mathrm{k} m$ is solved, the problem of length $m+1$ can be easily solved then.

For each node, the state transition equation from time stage $t$ to $t+1$ is described as

$$
S_{n_{i}, t+1}= \begin{cases}S_{n_{i}, t}+1 & X_{n_{i}, t}=0 \\ 0 & X_{n_{i}, t}=1\end{cases}
$$

where $S_{n_{i}, t}$ is the stage of a node at time $t$, which is denoted as the age of each intersection; $S_{n_{i}, t}$ is 0 when the intersection is changed to an interchange node.
Then, the multistage DP model for PCDN is formulated as follows:

$$
\min \sum_{t=1}^{T} \sum_{n}^{N} C_{n_{i}, t}\left(S_{n_{i}, t}\right)
$$

where $C_{n_{i, t}}\left(S_{n_{i}, t}\right)$ is the cost for each node $n_{i}$ at the year $t$ when the age of the intersection is $S_{n_{i}, t}$, which can be expressed as

$$
C_{n_{i}, t}\left(S_{n_{i}, t}\right)=C_{n_{i}, t}^{\mathrm{c}}\left(S_{n_{i}, t}\right)+C_{n_{i}, t}^{\mathrm{d}}\left(S_{n_{i}, t}\right) .
$$

$C_{n_{i}, t}^{\mathrm{d}}\left(S_{n_{i}, t}\right)$ is the delay cost due to the traffic congestion for PCDN, which is influenced by the growth of fuel consumption and labor cost which consists of wages for truck drivers, as shown in

$$
\begin{aligned}
C_{n_{i}, t}^{\mathrm{d}} & =C_{n_{i}, t}^{\text {fuel }}+C_{n_{i}, t}^{\text {human }} \\
C_{n_{i}, t}^{\text {fuel }} & =\alpha_{t}^{\text {car }} E_{n_{i}, t}^{\text {car }}+\alpha_{t}^{\text {truck }} E_{n_{i}, t}^{\text {truck }} \\
C_{n_{i}, t}^{\text {human }} & =\beta_{t}^{\text {car }} E_{n_{i}, t}^{\text {car }}+\beta_{t}^{\text {truck }} E_{n_{i}, t}^{\text {truck }}
\end{aligned}
$$

where $C_{n_{i}, t}^{\text {fuel }}$ and $C_{n_{i}, t}^{\text {human }}$ are fuel consumption and labor cost, respectively; $E_{n_{i}, t}^{\text {car }}$ and $E_{n_{i}, t}^{\text {truck }}$ are the average delay time of cars and trucks for each node at time $t ; \alpha_{t}^{\text {car }}$ and $\alpha_{t}^{\text {truck }}$ are the 
fuel cost at low speed for cars and trucks; and $\beta_{t}^{\text {car }}$ and $\beta_{t}^{\text {truck }}$ represent the salary of car drivers and truck drivers.

Some constraints are described as follows.

$$
\begin{aligned}
\sum_{t=1}^{T} \sum_{n}^{N} C_{n_{i}, t}^{\mathrm{c}}\left(S_{n_{i}, t}\right) & \leq B \\
X_{n_{i}, t}\left(1-X_{n_{i}, t}\right) & =0 \\
X_{n_{i}, t} & \leq X_{n_{i}, t+1} \\
E_{n_{i}, t}^{\mathrm{car}} & \leq e
\end{aligned}
$$

where $B$ is the total budget for construction investment and $e$ is an upper limit, which can be defined by users.

Constraint (8) limits the decision variable $X_{n_{i}, t}$, while (9) indicates that the construction of interchanges is irreversible. Equation (10) means that the delay time has an upper limit.

An optimal interchange construction scheduling solution is searched to minimize the whole cost from the year 1 to the lifetime $T$. In order to obtain $E_{n_{i}, t}^{\text {car }}$ and $E_{n_{i}, t}^{\text {truck }}$, simulation models are built as a black box to output the values of delay time.

\subsection{Simulation Model}

3.3.1. Simulation Model Assumption. (a) Once a crane begins to serve a vessel, it cannot move to another vessel, unless the operations of the vessel are finished.

(b) Machinery breakdowns and required repairs of the equipment are not modeled.

(c) Traffic assignment follows the principle of choosing segments with minimal traffic impedance.

3.3.2. Simulation Model Establishment. In this paper, a forecasting simulation model of traffic volume is established to analyze the relationship between port throughput and the traffic volume at port gates. This simulation model simulates the whole process in port (as shown in Figure 4). The results of the traffic volume forecast are taken as the inputs of the microscopic simulation model of the network. Then, the delay time can be obtained after running the microscopic simulation model.

Simulation Model I: Forecasting Model of Traffic Volume at Port Gates. An object-oriented simulation model is presented by using ARENA 10.0 software to simulate the whole process of operations inside a port transportation network. We take the import process in a container port as an example to describe Simulation Model I. The export process is almost the opposite.

(1) The Ships' Arrival and Departure Submodule. This submodule describes the process of ships' arrival and departure after the loading and unloading process, as shown in Figure 5.

A vessel arrives at ports following shipping schedule or a kind of probability distribution that users can define. The vessel is assigned with its attributes, like the speed, tonnage, and container volume, in the Create Module. Then the vessel goes through the waterway or waits for berthing at anchorages until a berth with the same tonnage is available.
After unloading and loading containers in the handling submodule, the vessel will leave the port through the waterway under the rule that users could define.

(2) The Handling Submodule. This submodule simulates loading and unloading process, transportation of the trucks inside the port, and operation process in yards, as shown in Figure 6.

When the vessel is berthing at a berth, trucks will wait under the quay cranes if they are not busy, or they will not come back to the berth until finishing their job. The truck inside the port travels following the shortest path rule. When a truck is loaded at the quay side, it will transport the containers to assignment blocks and wait for an unoccupied yard crane to unload the containers. All the facilities' handling time follows probability distributions that are user-defined according to the particular case, for example, a triangular distribution or a uniform distribution. For our case study in Section 4, the handing time for each yard crane follows a triangular distribution with the mean of $1.5 \mathrm{~min}$.

(3) The Truck Transport Submodule. The trucks' arrival and departure are simulated in this submodule, as shown in Figure 7.

For the import containers, the external truck will come to pick them up and send them out of the port after a period of storage time, which follows a kind of probability distribution.

As shown in Figure 6, it is necessary to allocate the bin area to the container to determine the target bin area for each external truck in advance. In addition, the inspection of containers is also considered in the model.

(4) The Traffic Calculation Submodule. As shown in Figure 8, this module is used to calculate the number and time of drayage trucks. According to the storage period provided by logistic companies, we can get the truck pick-up schedule for these containers. Then, the arrival and departure time for each external truck can be obtained based on the real operation process, which is described in the submodule.

Simulation Inputs. The model has a lot of user-defined constants, such as the number of berths, the size of yard, and the number of facilities. Besides, other inputs, like the arrival time of vessels and external trucks, the handling time of facilities, and the storage time of containers in the yard, are stochastic. Here, we take the distribution rule of arrival ships as an example to show how we deal with the stochastic input factors.

The distribution law is obtained by using the method of Chi-square test. Many ports in China, such as Ningbo port, Guangzhou port, and Dalian port, are taken as samples to try to discover the regularity. The results are shown as follows.

(1) Distribution of the Number of Arrival Ships per Day. For most of the container ports, the distribution of the number of arrival ships per day follows Poisson distribution, as shown in Figure 9.

Only for a small number of large-scale container ports, whose shipping lines are comparatively monotonous, the distribution obeys normal distribution, as shown in Figure 10. 


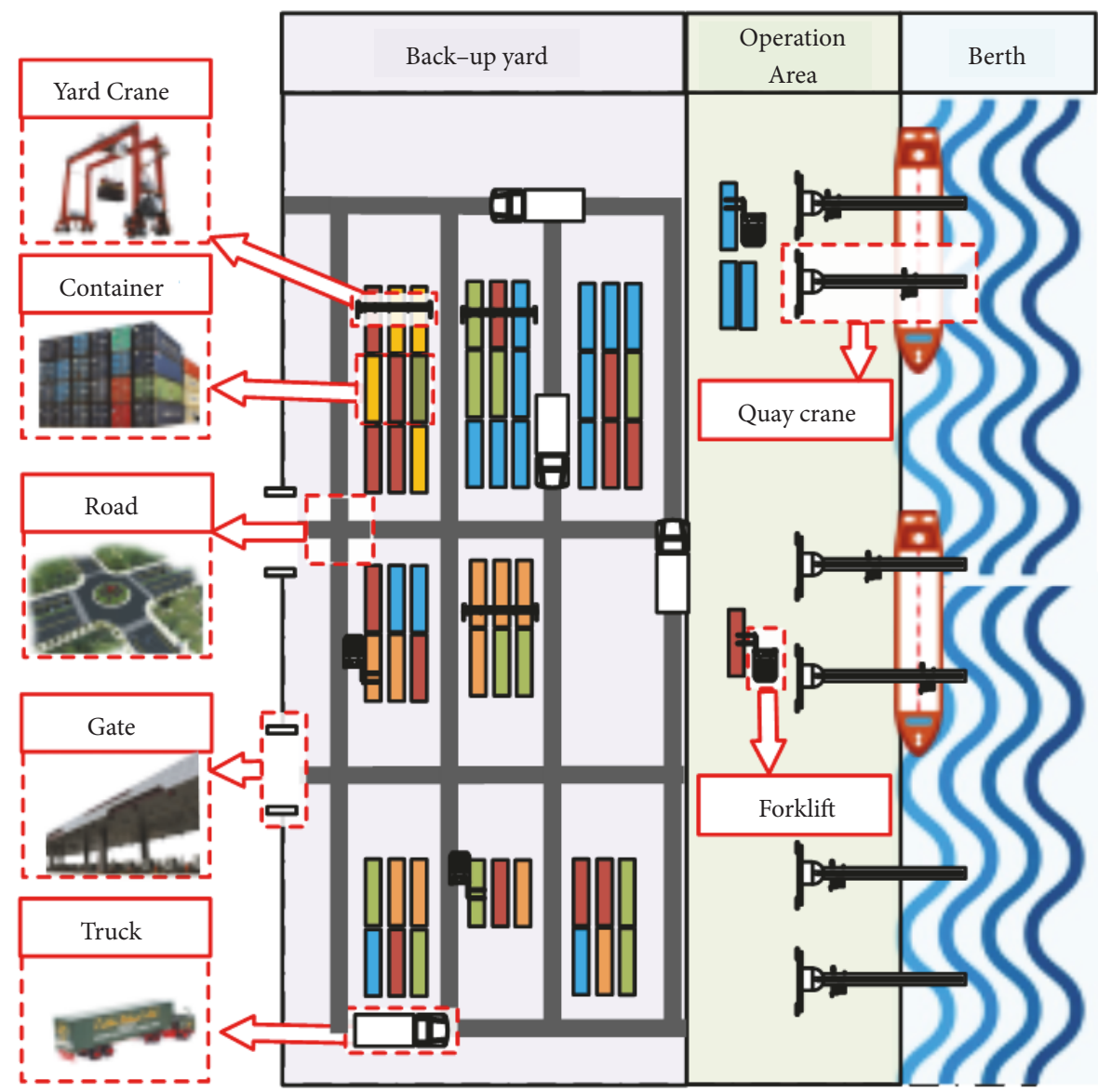

FIGURE 4: The operating process in a port.

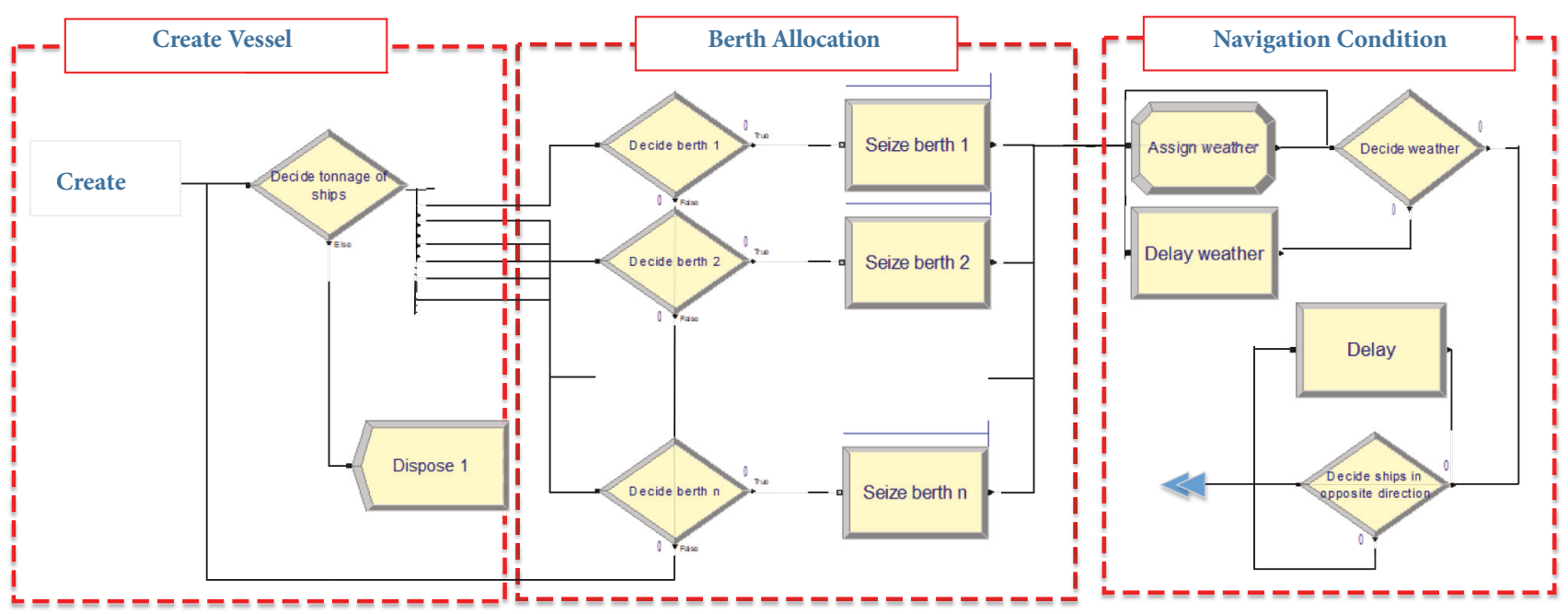

FIGURE 5: The ships' arrival and departure submodule. 


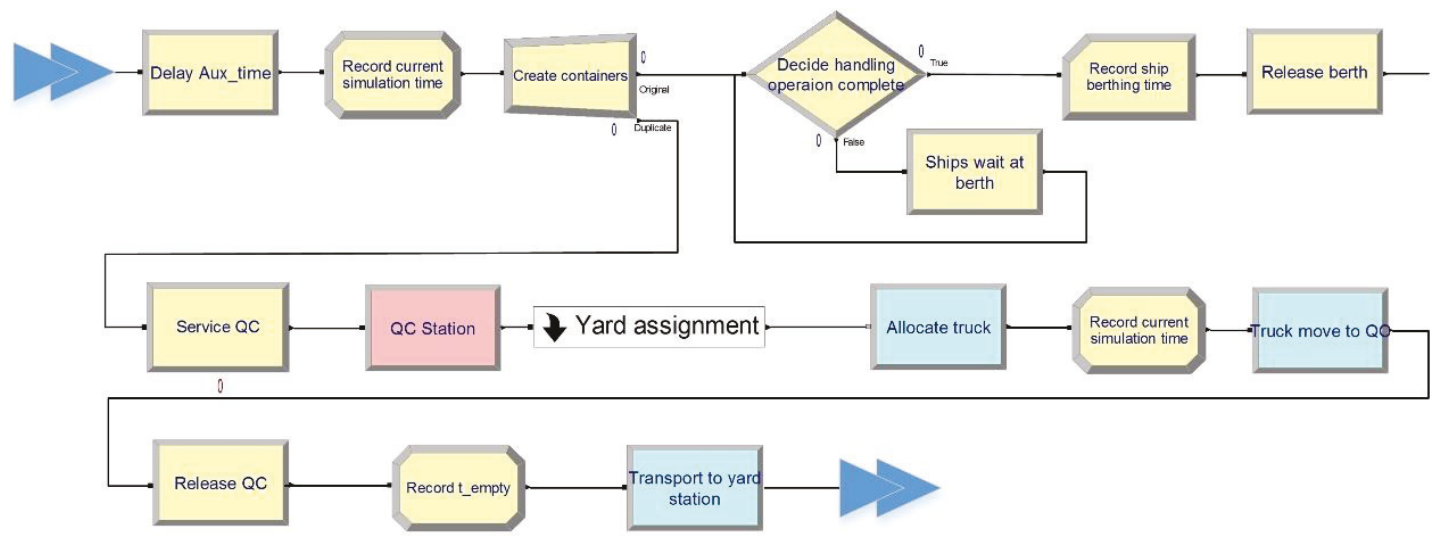

Figure 6: The handling submodule.

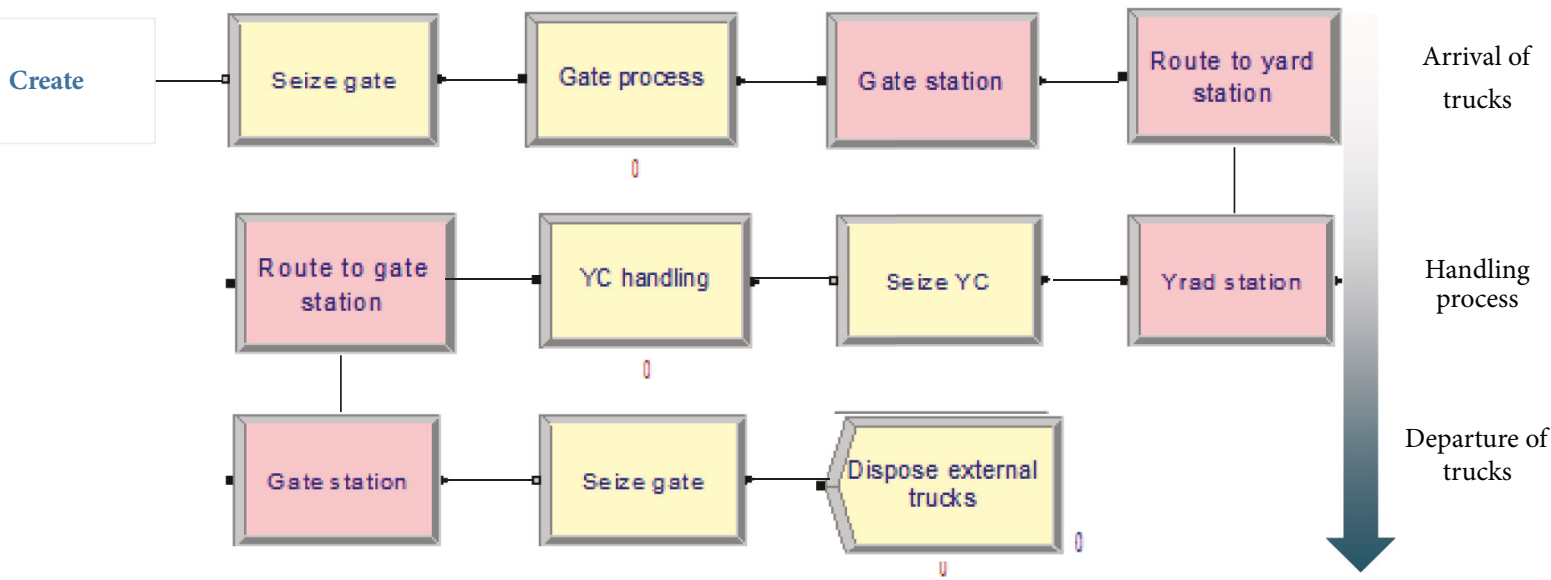

FIGURE 7: The truck transport submodule.

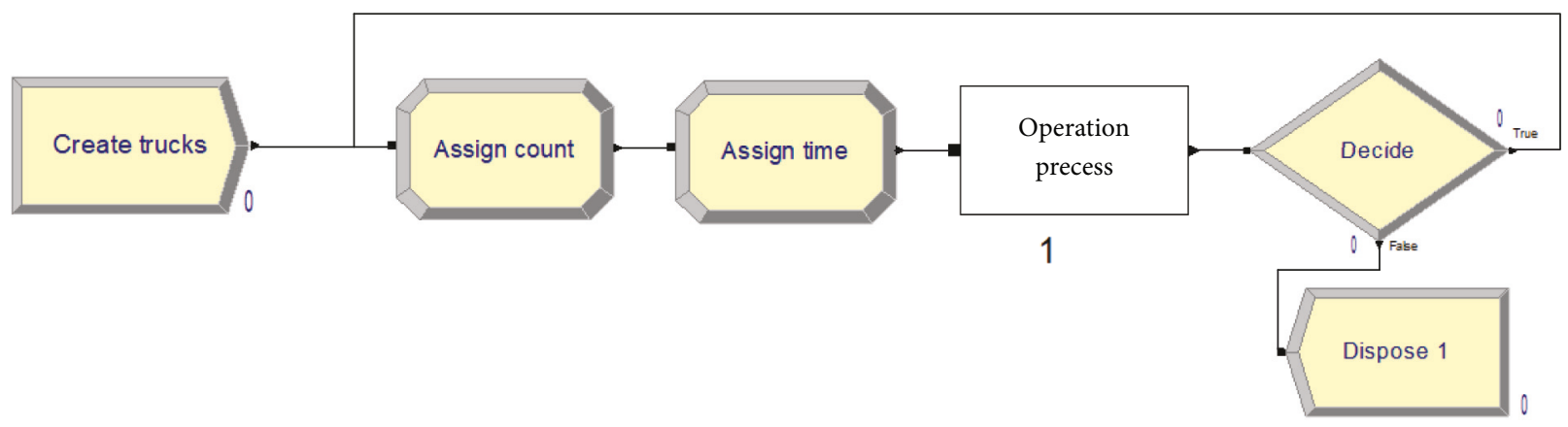

FIGURE 8: The truck transport submodule.

(2) Distribution of the Interarrival Time of Ships. Figure 11 shows that the interarrival time of ships for most of the ports in China obeys negative exponential distribution.

Simulation Outputs. The outputs from the model are the arriving and leaving time of each ship and truck. We can also calculate the service level of the port, the waiting time for each ship and truck, and the working time of all facilities. Then the traffic volume at each gate of ports can be obtained.

\section{Simulation Model II: Microscopic Traffic Simulation Model} for Nodes

(1) Forecast of Traffic Generative Volume in PCDN. The traffic volume in PCDN includes two parts: freight traffic volume and passenger traffic volume. The passenger traffic volume can be obtained based on the layout of PCDN. For example, as shown in Figure 12, PCDN area is divided into many blocks, such as banking and insurance business, hotels and resorts 


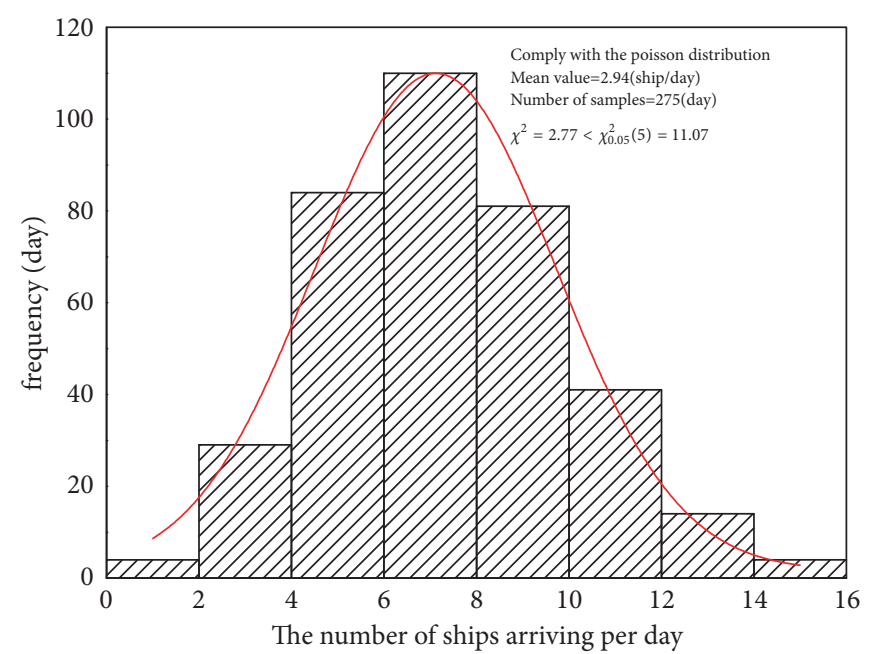

(a) Ningbo container port

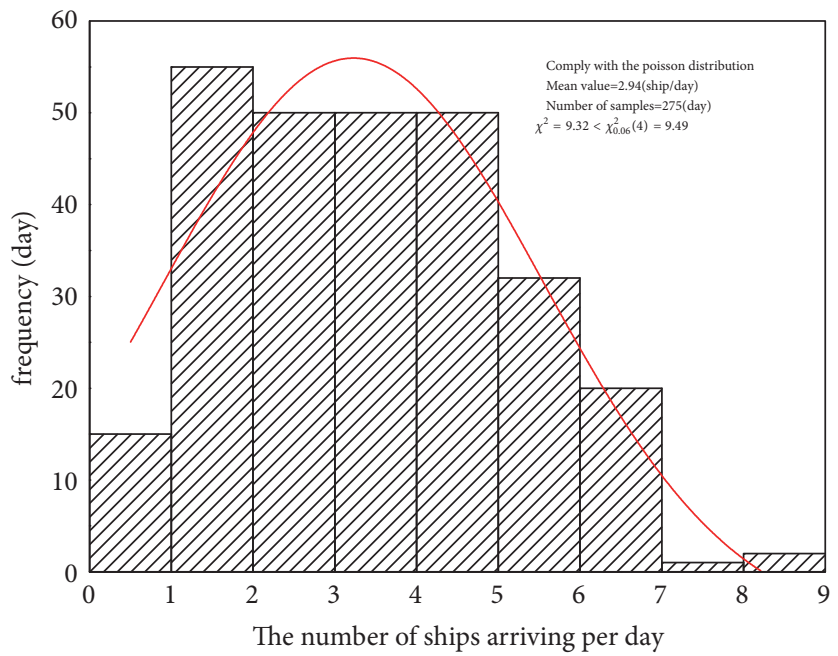

(b) Guangzhou container port

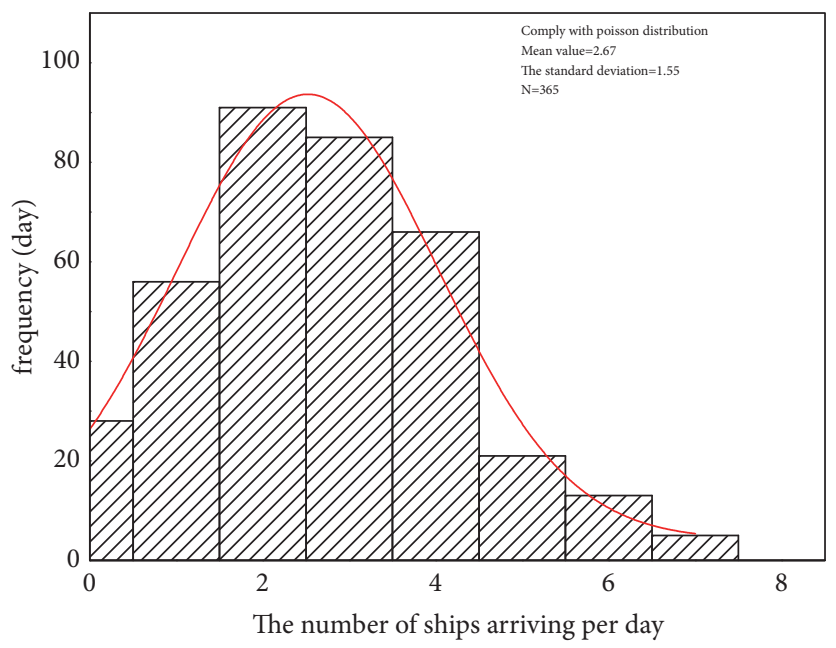

(c) Dalian container port

FIgURE 9: Poisson distribution of the number of arrival ships.

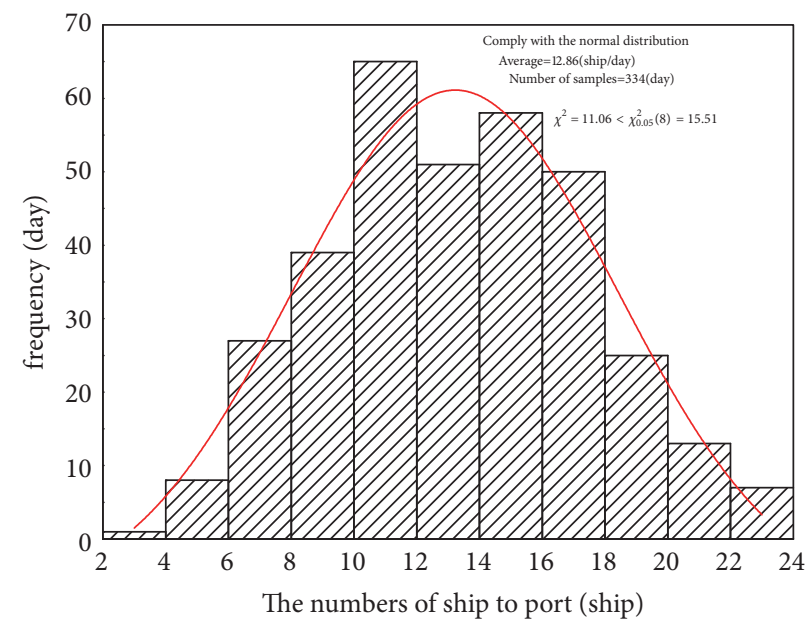

(a) Yantian International container port

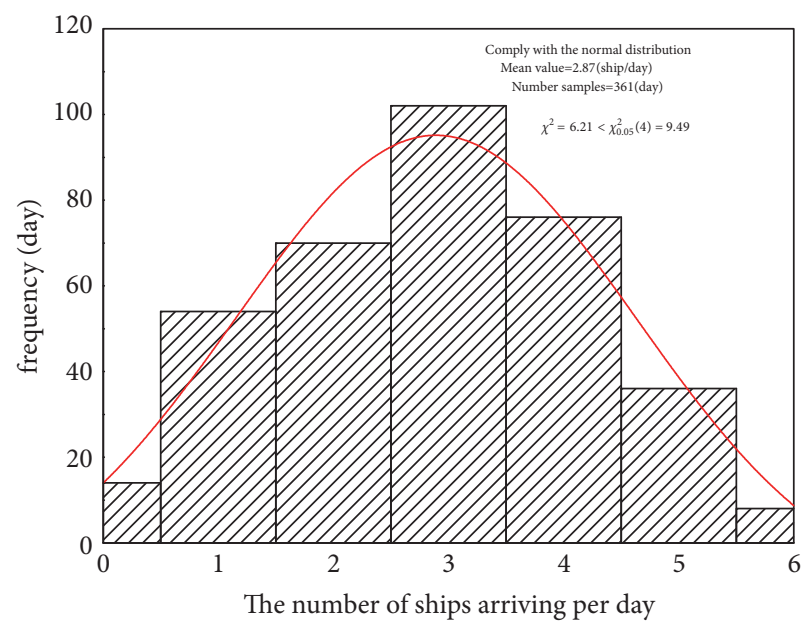

(b) Yantai Huanqiu port

FIGURE 10: Normal distribution of the number of arrival ships. 


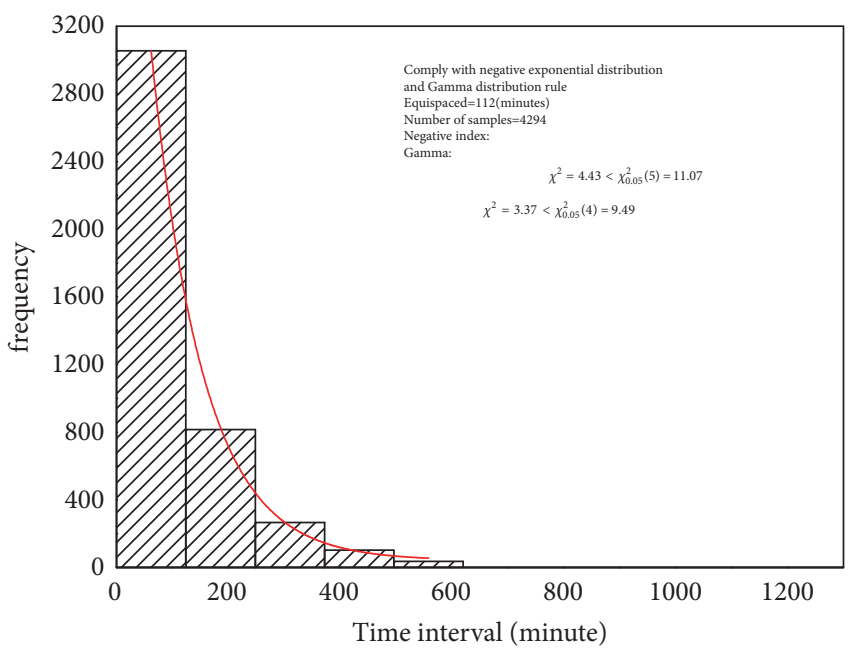

(a) Yantian international container port

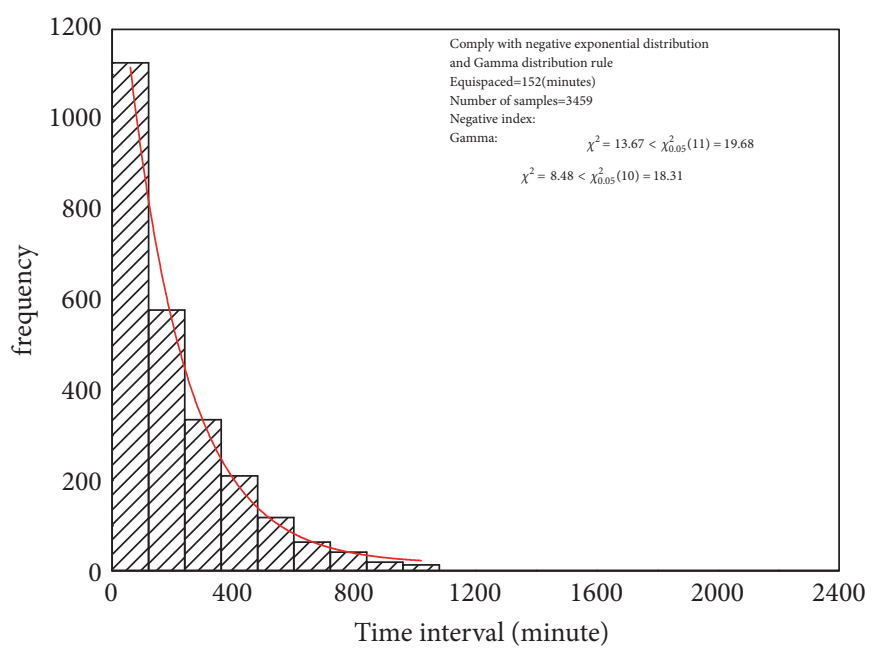

(b) Ningbo container port

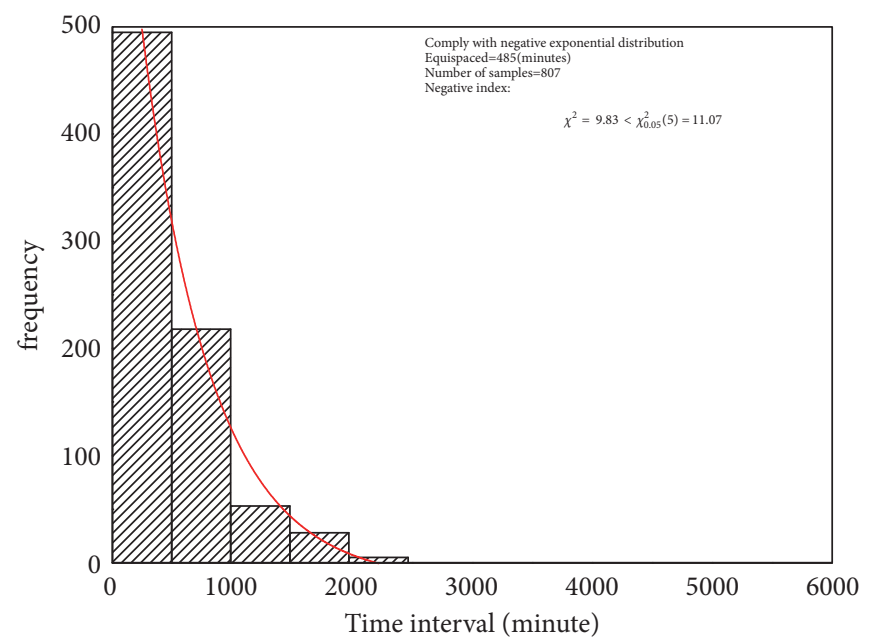

(c) Guangzhou container port

FIGURE 11: Distribution of the interarrival time of ships.

area, residential area, and retail center. Each block in PCDN can be regarded as the origin and destination node. Then, the traffic volume generated for each block can be forecast by the four-stage method according to the methodology proposed by the Institute of Transportation Engineers [26].

Besides, there are several logistic zones in PCDN, which will cause freight traffic for the network. For a certain logistic zone, the size, function, and cargo volume handled each year are known, which are provided by urban planning and design institutes. Then, the average freight traffic volume for each zone can be obtained.

The other part of the freight traffic volume is obtained from Simulation Model I. The traffic volume changes over time, and the average traffic volume and the volume at morning and evening peak are taken as an example in this paper.

(2) Trip Distribution Forecast. For the passenger traffic volume, the trip distribution is forecast by dual-constrained gravity model [27].
The freight traffic volume is divided into two parts: the traffic distribution from port and modern logistics areas. The destination nodes of the freight traffic for PCDN are few and clear, such as the harbor highway junction. Then, the trip distribution can be forecast according to the historical data provided by port and logistics companies. If no historical data is available, the proportion of freight volume for each destination node in PCDN can be estimated by questionnaire or taking into account cargo final destination, which is not the focus of this paper.

(3) Model Establishment. The traffic volume in PCDN and trip distribution forecast work as the inputs of the TransCAD model. TransCAD is used in the paper based on real map, which combines GIS and transportation modeling in a single integrated platform. The network can be built in TransCAD model with the attributes of roads and nodes, such as the length, speed, capacity, width, and type (trunk, subarterial, branch, etc.) of links, the number of lanes, and the type of intersections. Stochastic User Equilibrium Method and 


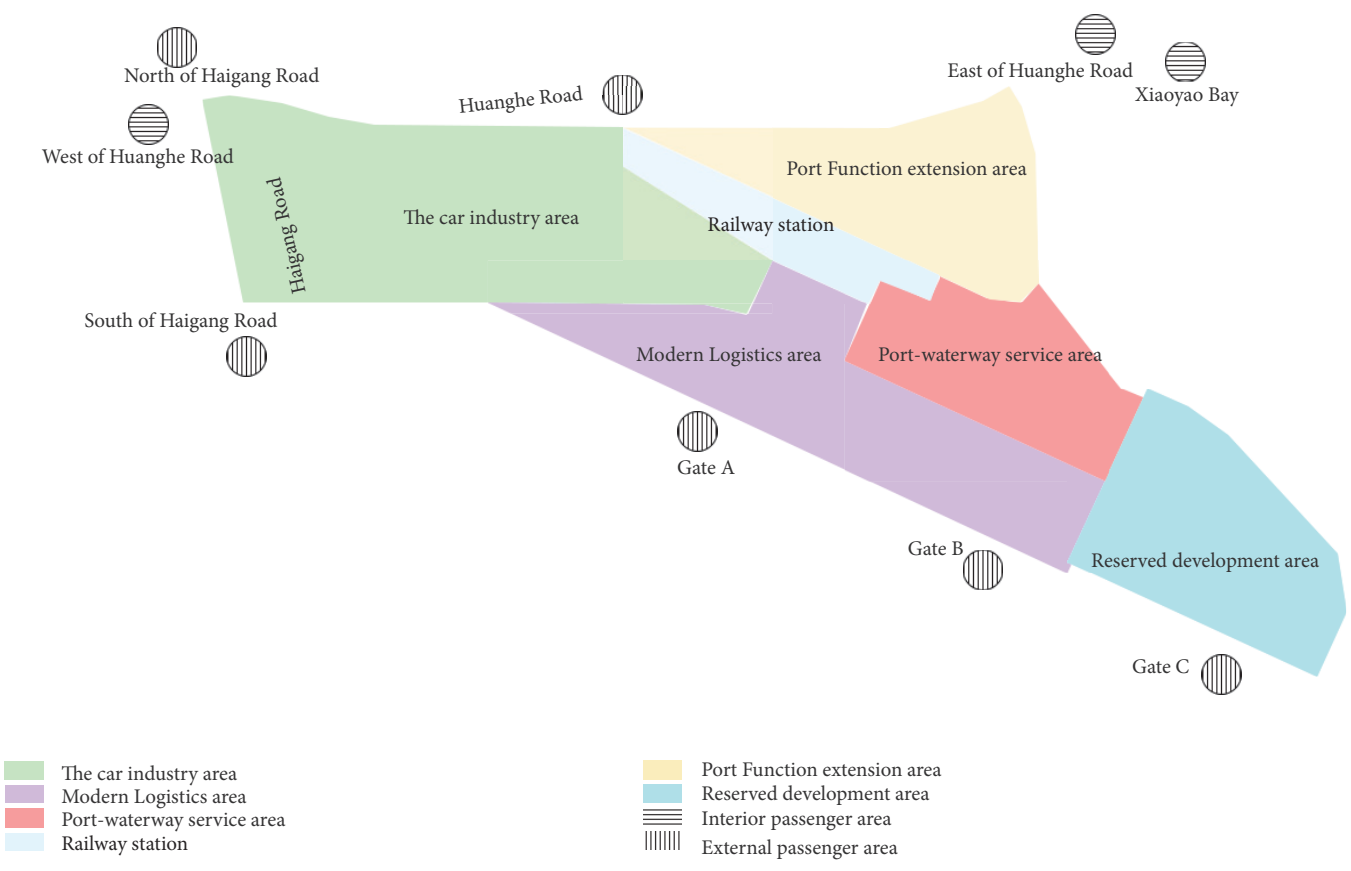

FIGURE 12: Different functional regions in PCDN.

System Optimum or Incremental Method can be applied for traffic assignment. Then, the traffic volume for each link and node can be obtained in Transit Flow layer after running the model, as shown in Figure 13.

Instead of the mathematical model and macroscopic model, the microscopic traffic flow simulation model can describe the behavior of vehicles in detail which is an efficient way to study the traffic conditions in each road intersection. Thus, on the basis of the VISSIM software, we built the microscopic traffic model for PCDN. The result traffic volume of TransCAD model will be input as parameters in this microscopic traffic simulation model.

According to actual road network, the information including the road width and direction can be obtained. Every road section is described by a directed Link module. The Connector module connects different road sections, as shown in Figure 14. There is a conflict area where two connectors overlap. In conflict areas, traffic flow will be controlled by the signal and priority rule. Based on Link module and Connector module, as previously mentioned, the PCDN is constructed.

To simulate the microbehavior of the vehicles in the actual road network, such as car-following and lane-change, four modules in the simulation software VISSIM, namely, environment construction, vehicle driving simulation, traffic control simulation, and path selection simulation, are applied to carry out the microsimulation analyses. The average delay time of vehicles through the cross node in every road section can be obtained from the data detectors set at each road section of the cross node.

\section{Case Study}

The case study is conducted based on a real project in northern China. Container throughput capacity was 625 thousand
TEUs in 2015 and will rise over 7.3 million TEUs in 2030 according to the Port Plan. There is only one port gate before 2030, which is defined as Gate A, as shown in Figure 15. In 2030, Gates B and C will be put into use. PCDN, the yellow area in Figure 15, is composed of two transverse and three lengthwise arterial roads (red roads in Figure 15). Four key nodes are facing mounting traffic pressure. It is requested by local governments to help deicide construction time for the four intersections. Therefore, the simulation-based DP approach proposed in this paper is applied.

4.1. Model Inputs. According to the statistical data for this container port, the time interval of vessels' arrival follows negative exponential distribution. The number of vessels arriving per day follows Poisson's distribution. Bakshi et al. [28] draws a conclusion from the real data of two international container ports that the arrival pattern of drayage trucks follows the Poisson distribution. The number of nonoperating days due to natural conditions is about 15 days per year. The storage period for imported containers is 7-10 days and for exported containers is 3-5 days. The predicted values of throughput and the number of vessels per year can be obtained from Port Plan. Due to the length of the paper and the principle of confidentiality, the throughput and the number of vessels and berths for three representative years, 2015, 2020, and 2030, are listed in Table 1 as an example. At this time, we imagine the time period is 16 years, which means the construction decision for each node should be made from the year $2015(t=0)$ to 2030 .

According to local statistical data and planning data from governments and logistics companies, the passenger traffic volume and freight traffic volume from urban area and local logistics zones are listed in Table 2 for three representative years, 2015, 2020, and 2030. The freight traffic 


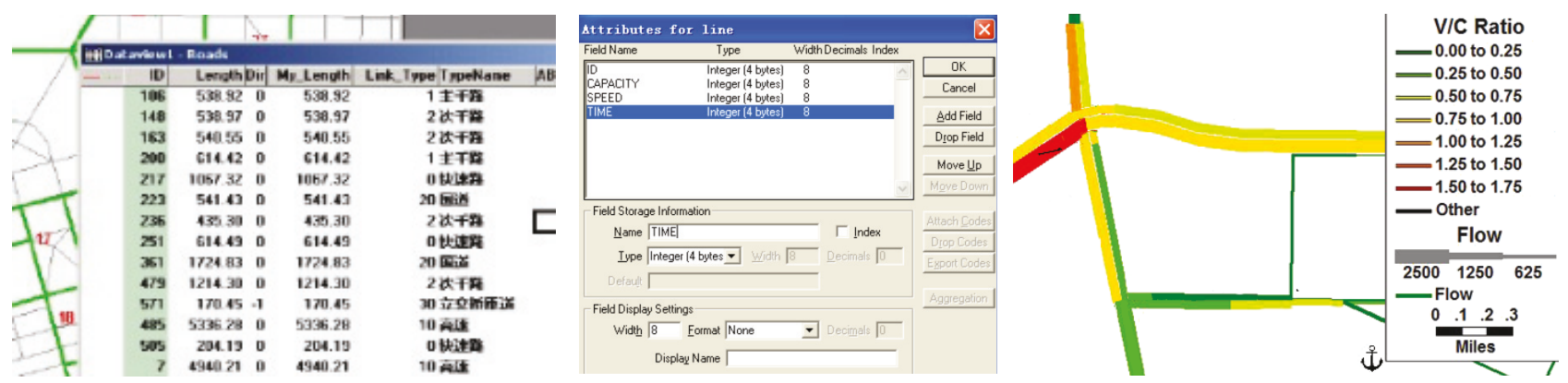

FIgURE 13: Traffic volume obtained from TransCAD model.

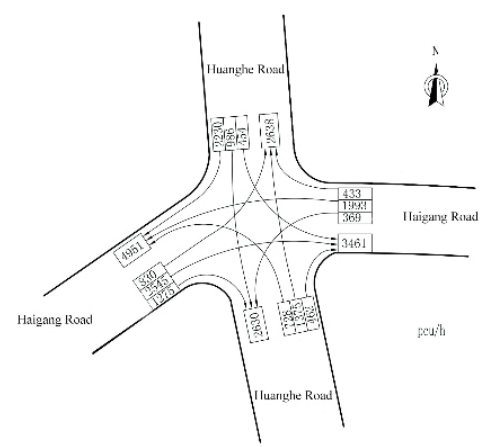

(a) Traffic volume obtained from TransCAD

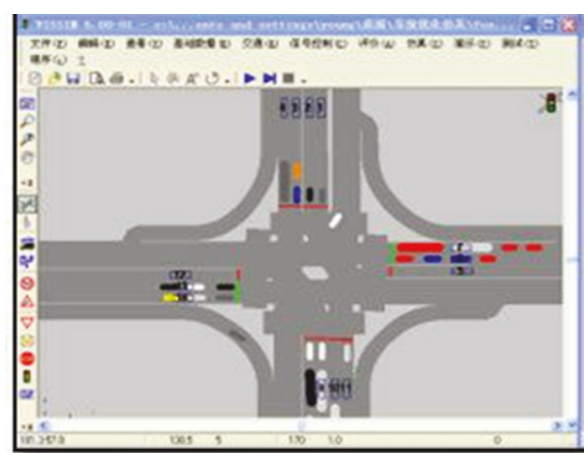

(b) Microscopic traffic model for a crossing

Figure 14: The microscopic traffic model in VISSIM.

volumes from ports are generated from Simulation Model I. Then, TransCAD is used to generate the total traffic flow distribution in PCDN every time. After that, parameters, such as the driving behavior used in VISSIM, are shown in Table 3. Among them, car-following module is Wiedemann 74.

According to the construction data provided by design companies, the cost for $n_{1}, n_{3}$, and $n_{4}$ nodes is about 105 million yuan, while the cost is 140 million yuan for $n_{2} . \beta_{t}^{\text {car }}$ and $\beta_{t}^{\text {truck }}$ are 5.8 and 4.5 thousand yuan per month, while $\alpha_{t}^{\text {car }}$ and $\alpha_{t}^{\text {truck }}$ are 10.8 and 7.2 yuan per hour.

4.2. Results. The output traffic volumes at port gate node obtained from Simulation Model I are shown in Table 4 for three representative years, 2015, 2020, and 2030. Figure 16 shows an example result of trip distribution for passenger traffic volume in the year 2015. Figures 17-19 take the network without interchanges in the years 2015, 2020, and 2030 as an example to show how the traffic volume is presented from TransCAD. Huanghe Road and Huaihai Road are going to face great traffic pressure. Figure 20 takes the network with one interchange for the node $n_{1}$ as an example to demonstrate how the traffic volume is influenced by changing intersections to interchanges. Based on the traffic volume in PCDN, VISSM simulates the complex behavior in road network and output the delay time every year.

In order to eliminate the influence of system errors, output results of the microcosmic simulation model are the average data on the basis of 10 replications. We use the reverse iteration algorithm, as stated in Section 3.2, to solve this simulation-based DP problem based on MATLAB. The optimal results are $\left(0,0,1_{1}, 1_{2}, 125036.9\right)$. Results are shown in Table 5. The results show that the construction of node 3 should be completed in 2016, and node 4 should be completed in 2018. The minimum cost is 1250 million yuan.

In addition, given that the construction cost for each node is influenced by many factors, such as the type and the numbers of lanes, a sensitivity analysis of the construction cost changing from 75 million yuan to 240 million yuan has been taken, as shown in Table 6 .

In Table 6, when the construction cost is 75 million yuan for nodes 1,3 , and 4 , the construction schedule is that nodes 2 and 4 should be completed in 2016; when the cost is 90 million yuan, nodes 2 and 3 should be completed in 2018 . The construction scheme changes with the growth of construction cost, but the number of nodes needs to be changed so that interchanges remain the same. In other words, two nodes should be retrofitted to ensure that the road network is expeditious and efficient. What is more, the proportion of construction cost keeps almost the same with the increasing of construction cost, which is about $20 \%$ of the total cost.

In order to evaluate the aforementioned method, we conduct an experiment based on a traditional method that the most congested intersections will be changed to interchanges with the increase of the port throughput. Results of the traditional method show that when the throughput of ports increases to 7 million TEUs, only node 2 needs to be completed. Table 7 gives the vehicle delay time after reconstruction of these two methods. 
TABLE 1: The throughput and the number of vessels for three representative years.

\begin{tabular}{lccc}
\hline Year & 2015 & 2020 & \\
\hline Throughput/million TEUs & 0.625 & 1.1 & 2030 \\
\hline The number of vessels & 328 & 651 & 7.3 \\
\hline The number of berths & 1 & 2 & 3789 \\
\hline
\end{tabular}

TABLE 2: Traffic volume from urban area and logistics zones for three representative years, 2015, 2020, and 2030.

\begin{tabular}{|c|c|c|c|c|c|}
\hline \multirow{3}{*}{ Year } & \multicolumn{4}{|c|}{ Passenger traffic volume } & \multirow{3}{*}{$\begin{array}{l}\text { Freight traffic volume from } \\
\text { logistics zones } \\
\text { The number of trucks per } \\
\text { day }\end{array}$} \\
\hline & \multicolumn{2}{|c|}{ The number of pedestrian per day } & \multicolumn{2}{|c|}{$\begin{array}{l}\text { The number of motor vehicles per } \\
\text { day }\end{array}$} & \\
\hline & Attractions & Productions & Attractions & Productions & \\
\hline 2015 & 23118 & 23358 & 10869 & 9678 & 1120 \\
\hline 2020 & 36114 & 28890 & 26178 & 20763 & 2240 \\
\hline 2030 & 39816 & 30447 & 30516 & 23874 & 13082 \\
\hline
\end{tabular}

TABLE 3: Calibrated parameters of the microcosmic simulation model.

\begin{tabular}{lccccc}
\hline Parameters & \multicolumn{2}{c}{ Parameters of car following behavior } & \multicolumn{2}{c}{ Parameters of lane changing behavior } \\
Average stopping & $\begin{array}{c}\text { Addition safe } \\
\text { distance } / \mathrm{m}\end{array}$ & $\begin{array}{c}\text { Multiples of safe } \\
\text { distance } / \mathrm{m}\end{array}$ & $\begin{array}{c}\text { Maximal } \\
\text { deceleration } /\left(\mathrm{m} \cdot \mathrm{s}^{-2}\right)\end{array}$ & $\begin{array}{c}\text { Acceptable } \\
\text { deceleration } /\left(\mathrm{m} \cdot \mathrm{s}^{-2}\right)\end{array}$ & $\begin{array}{c}\text { Minimum space } \\
\text { headway } / \mathrm{m}\end{array}$ \\
\hline $\begin{array}{l}\text { Adjusted } \\
\text { value }\end{array}$ & 2.00 & 2.75 & 3.75 & -4.20 & -1.30 \\
\hline
\end{tabular}

TABLE 4: The traffic volume at port gate in three representative years.

\begin{tabular}{|c|c|c|c|}
\hline Year & Gate & The maximum truck number per day & The average truck number per day \\
\hline 2015 & $\mathrm{~A}$ & 132 & 74 \\
\hline 2020 & $\mathrm{~A}$ & 242 & 160 \\
\hline \multirow{3}{*}{2030} & $\mathrm{~A}$ & 586 & 360 \\
\hline & $\mathrm{B}$ & 534 & 373 \\
\hline & $\mathrm{C}$ & 422 & 280 \\
\hline
\end{tabular}

TABLE 5: Results of simulation-based optimization model.

\begin{tabular}{lccc}
\hline Node number & \multicolumn{2}{c}{ Values } & Construction time \\
\hline 1 & $\mathrm{X}$ & Average delay time(s) & -- \\
2 & 0 & 45.7 & -- \\
3 & 0 & 22.9 & 2016 \\
4 & 1 & 19.7 & 2018 \\
\hline
\end{tabular}

TABLE 6: Sensitivity analysis of the construction cost of interchanges.

\begin{tabular}{lccc}
\hline $\begin{array}{c}\text { Construction cost } \\
\text { (million yuan) }\end{array}$ & Complete node 2 and 4 in 2016 & $\begin{array}{c}\text { Total cost } \\
\text { (million } \\
\text { yuan) }\end{array}$ \\
\hline 75 & 100 & Comstruction Scheme & 743.872 \\
90 & 120 & Complete node 3 in 2016, while node 4 in 2018 & 1027.465 \\
105 & 140 & Complete node 2 and 4 in 2022 & 1250.370 \\
120 & 160 & Complete node 2 in 2020, while node 4 in 2022 & 1380.727 \\
135 & 180 & Complete node 3 and 4 in 2020 & 1488.410 \\
150 & 200 & Complete node 2 in 2020, while node 4 in 2022 & 1602.452 \\
165 & 220 & Complete node 3 and 4 in 2022 & 1558.410 \\
180 & 240 & & \\
\hline
\end{tabular}




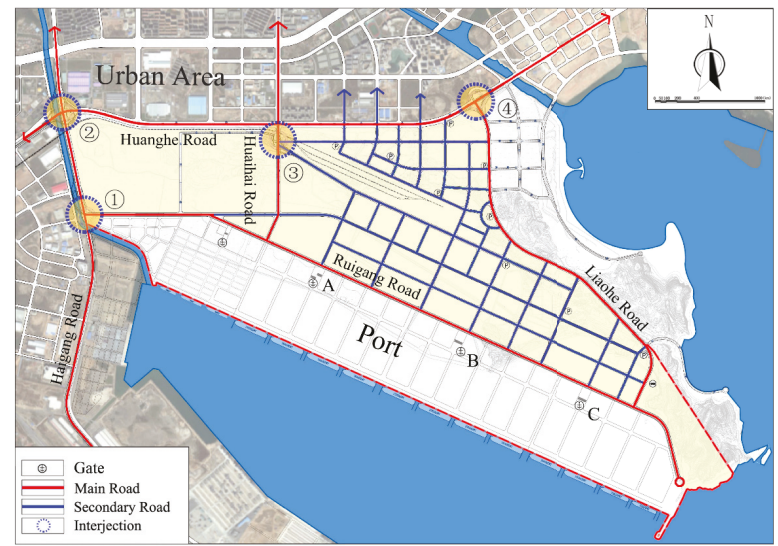

FIGURE 15: A real project in northern China.

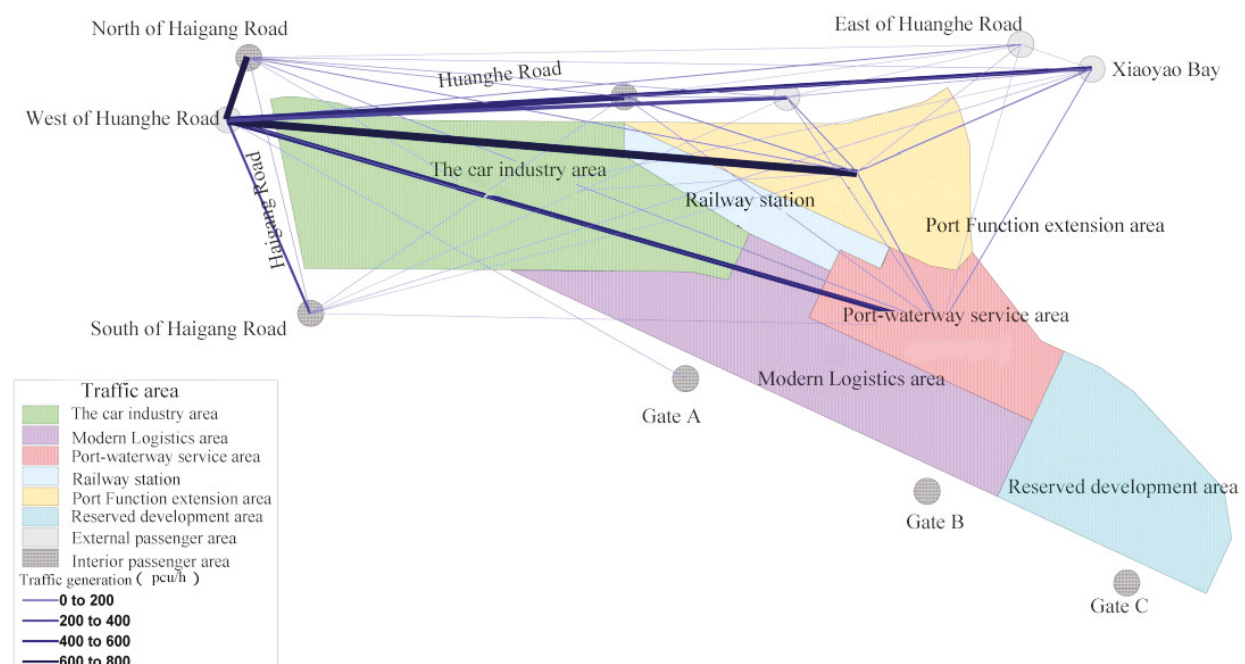

FIGURE 16: The travel forecasting of motor vehicles in 2015.

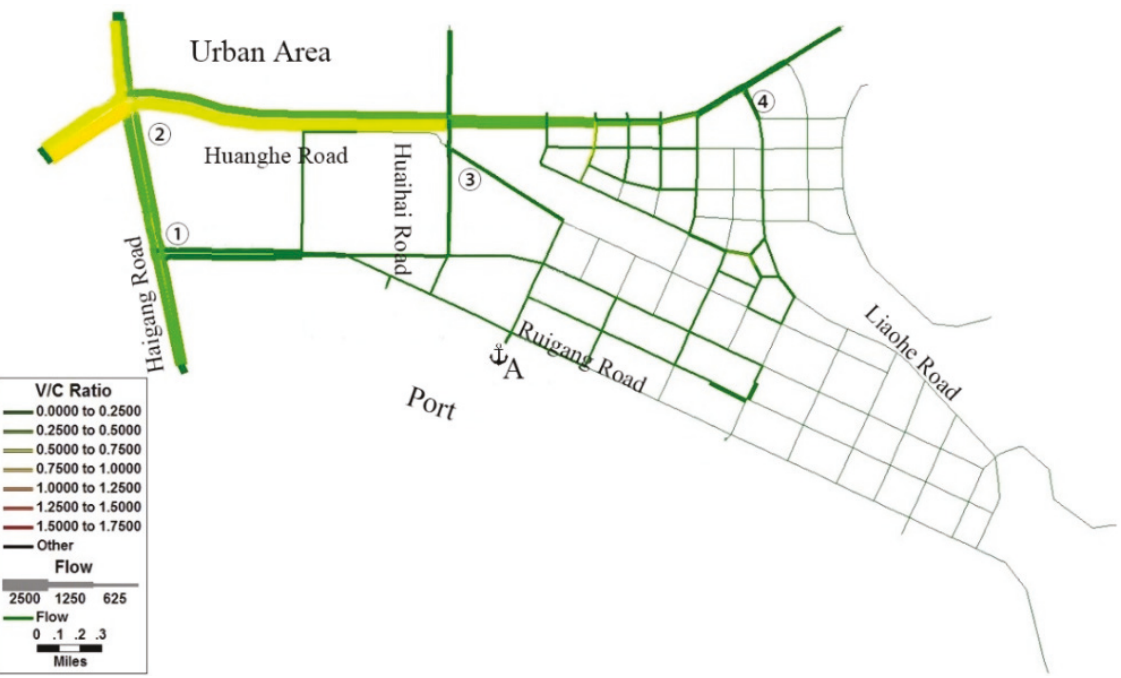

FIGURE 17: The traffic volume of PCDN in 2015 without interchange. 


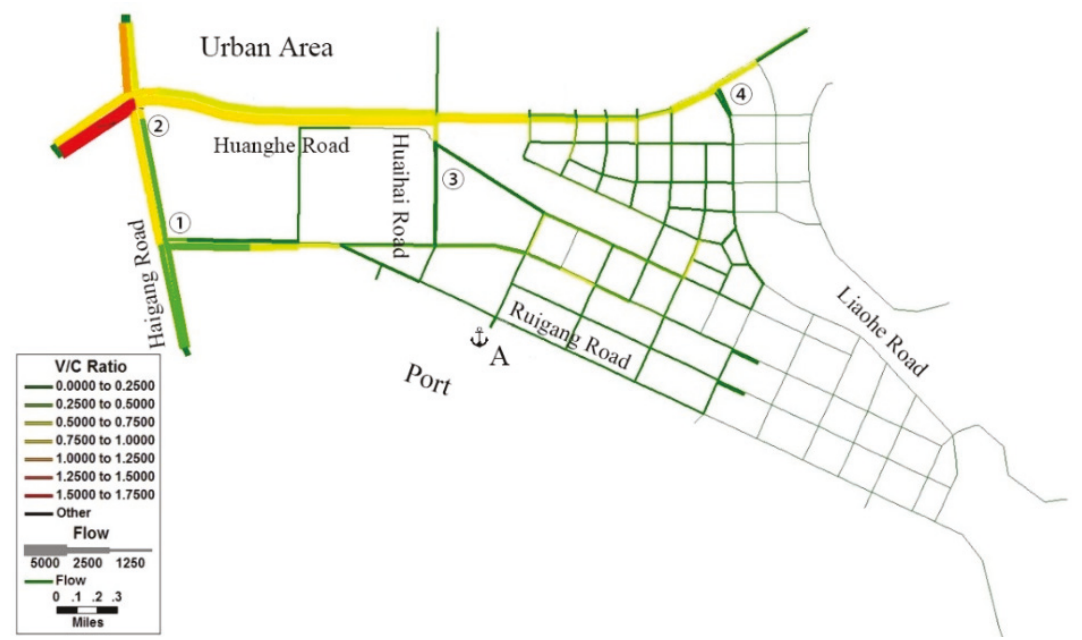

FIGURE 18: The traffic volume of PCDN in 2020 without interchange.

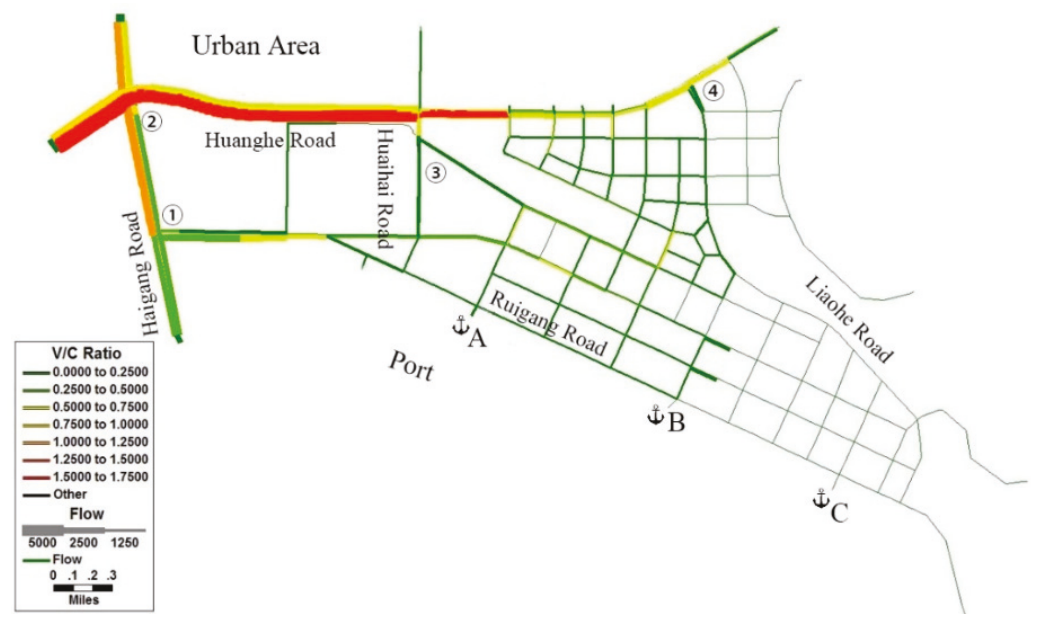

Figure 19: The traffic volume of PCDN in 2030 without interchange.

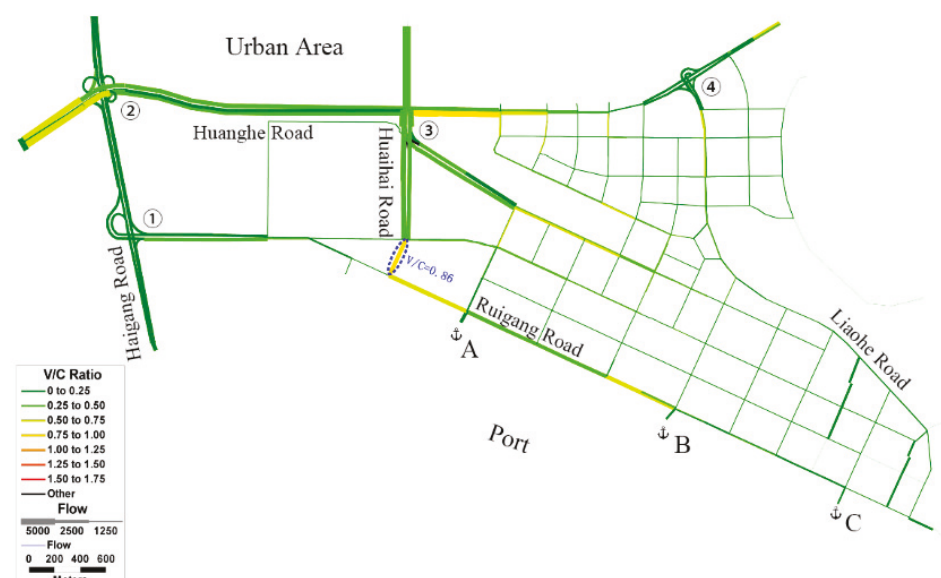

Figure 20: The traffic volume of PCDN in 2030 with one interchange. 
TABLE 7: Comparative analysis of results of two methods.

\begin{tabular}{|c|c|c|c|c|c|c|c|c|c|c|}
\hline \multirow{3}{*}{ Vehicle Type } & \multicolumn{5}{|c|}{ Traditional method } & \multicolumn{5}{|c|}{ A Simulation-based DP Method } \\
\hline & \multicolumn{4}{|c|}{ Average delay time(s) } & \multirow{2}{*}{ Total delay time(s) } & \multicolumn{4}{|c|}{ Average delay time(s) } & \multirow{2}{*}{ Total delay time(s) } \\
\hline & $1 \#$ & 2\# & 3\# & $4 \#$ & & $1 \#$ & $2 \#$ & 3\# & $4 \#$ & \\
\hline Urban Vehicles & 33.4 & 19.9 & 31.7 & 39.2 & 1923635.7 & 16.4 & 19.7 & 11.6 & 19.1 & 1385990.4 \\
\hline Drayage Trucks & 21.6 & 22.4 & 34.9 & 32.7 & 2137629.9 & 18.9 & 33.2 & 15.7 & 13.4 & 1096014.4 \\
\hline All Vehicles & 30.9 & 21.5 & 33.7 & 36.5 & - - & 17.3 & 26.9 & 13.6 & 14.7 & - \\
\hline
\end{tabular}

\section{Conclusions and Discussions}

As one of the effective methods to reduce congestion, grade intersection has already been changed to interchange in PCDN of ports. PCDN, which connects ports and urban transport systems, is influenced by both the port freight transportation and urban passenger traffic. Due to the growing of the demand for port freight transportation, congestion in PCDN is becoming one of the inevitable problems that need to be solved. Therefore, it is very important to provide a method to study which intersection should be changed to an interchange node in PCDN to minimize the whole cost during lifetime period under the dynamic change of traffic volume.

The main contribution of this paper is to provide a simulation-based DP approach to solve the interchange node construction scheduling problem in PCDN. A port operation simulation model (Simulation Model I) and a microscopic traffic simulation model (Simulation Model II) are combined together to output the delay time in PCDN, which works as the input of the DP model. The proposed method can help solve analogous complicated multistage problems, which can hardly be presented by a mathematical formula because of high uncertainties.

Results are obtained based on a real case study. From the case study, results show that interchange construction decisions are not made only based on the traffic volume at each node. Take the first line in Table 6 as an example, nodes 2 and 4 are completed in 2016 instead of nodes 2 and 3 whose traffic volumes are larger. Besides, with the increment of construction cost, two nodes at most in PCDN are changed to interchanges without budget constraints. For other case studies, the results may be changed due to different input parameters. However, the decision on which intersection should be changed to an interchange node in PCDN cannot be made only by the crossing's daily traffic volume, its connectivity to other facilities, or daily congestion time.

Further research on the issue of interchange node construction scheduling problem could proceed in several directions. For instance, the influence of interchange construction on the environment and land area should be considered for the next stage. Besides, the different construction work period needs to be taken into account.

\section{Data Availability}

The data used to support the findings of this study are available from the corresponding author upon request.

\section{Conflicts of Interest}

The authors declare that they have no conflicts of interest.

\section{Acknowledgments}

The authors would like to acknowledge the support of National Natural Science Foundation of China (nos. 51709037 and 51779037). In addition, the authors acknowledge the Research Center for Port Development at Dalian University of Technology for partial funding and devices.

\section{References}

[1] R. Bellman, "On the theory of dynamic programming," Proceedings of the National Acadamy of Sciences of the United States of America, vol. 38, pp. 716-719, 1952.

[2] R. Waddell, "Model for equipment replacement decisions and policies," Interfaces, vol. 13, no. 4, pp. 1-7, 1983.

[3] J. C. Hartman, "A Note on A Strategy for Optimal Equipment Replacement," Production Planning \& Control, vol. 16, no. 6, pp. 733-39, 2005.

[4] K. S. Moghaddam and J. S. Usher, "Preventive maintenance and replacement scheduling for repairable and maintainable systems using dynamic programming," Computers \& Industrial Engineering, vol. 60, no. 4, pp. 654-665, 2011.

[5] E. T. Bacalhau, F. L. Usberti, and C. Lyra, "A dynamic programming approach for optimal allocation of maintenance resources on power distribution networks," in Proceedings of the 2013 IEEE Power and Energy Society General Meeting, PES '13, pp. 1-5, IEEE, July 2013.

[6] J. S. D. Aversa and J. F. Shapiro, "Optimal machine maintenance and replacement by linear programming and enumeration," The Journal of the Operational Research Society, vol. 29, no. 8, pp. 759-768, 1978.

[7] W. Fan, R. B. MacHemehl, and M. D. Gemar, "Optimization of equipment replacement," Transportation Research Record, no. 2292, pp. 160-170, 2012.

[8] C. Liu, Y. Fan, and F. Ordó Ez, "A Two-Stage Stochastic Programming Model for Transportation Network Protection," Computers \& Operations Research, vol. 36, pp. 1582-1590, 2009.

[9] Y. Fan, C. Liu, R. Lee, and A. S. Kiremidjian, "Highway network retrofit under seismic hazard," Journal of Infrastructure Systems, vol. 16, no. 3, pp. 181-187, 2010.

[10] L. Gan and J. Xu, "Retrofitting Transportation Network Using a Fuzzy Random Multiobjective Bilevel Model to Hedge against Seismic Risk," Abstract and Applied Analysis, vol. 2014, Article ID 505890, 24 pages, 2014.

[11] Y. Dong, D. M. Frangopol, and S. Sabatino, "Optimizing bridge network retrofit planning based on cost-benefit evaluation and 
multi-attribute utility associated with sustainability," Earthquake Spectra, vol. 31, no. 4, pp. 2255-2280, 2015.

[12] C. Q. Guan and R. F. Liu, "Container terminal gate appointment system optimization," Maritime Economics \& Logistics, vol. 11, no. 4, pp. 378-398, 2009.

[13] G. Chen, K. Govindan, and Z. Yang, "Managing truck arrivals with time windows to alleviate gate congestion at container terminals," International Journal of Production Economics, vol. 141, no. 1, pp. 179-188, 2013.

[14] J. A. Pope, T. R. Rakes, L. P. Rees, and I. W. M. Crouch, "A network simulation of high-congestion road-traffic flows in cities with marine container terminals," Journal of the Operational Research Society, vol. 46, no. 9, pp. 1090-1101, 1995.

[15] K. Cartwright, L. Cottrill, G. Hamrick, M. Leue, and L. Nye, "Ports of Long Beach and Los Angeles Transportation Study," Transportation Research Record, no. 1820, pp. 26-35, 2003.

[16] B. Yu, C. Zhang, L. Kong et al., "System dynamics modeling for the land transportation system in a port city," Simulation, vol. 90, no. 6, pp. 706-716, 2014.

[17] J. Bilbao-Ubillos, “The costs of urban congestion: Estimation of welfare losses arising from congestion on cross-town link roads," Transportation Research Part A: Policy and Practice, vol. 42, no. 8, pp. 1098-1108, 2008.

[18] N. Garrido, "Computing the cost of traffic congestion: A microsimulation exercise of the City of Antofagasta, Chile," Transportation Planning and Technology, vol. 35, no. 8, pp. 752-768, 2012.

[19] K. G. Bardal and F. Jørgensen, "Valuing the risk and social costs of road traffic accidents - Seasonal variation and the significance of delay costs," Transport Policy, vol. 57, pp. 10-19, 2017.

[20] S. Jung, X. Qin, and D. A. Noyce, "Modeling highway safety and simulation in rainy weather," Transportation Research Record, vol. 2237, no. 1, pp. 134-143, 2011.

[21] W. Burgholzer, G. Bauer, M. Posset, and W. Jammernegg, "Analysing the impact of disruptions in intermodal transport networks: A micro simulation-based model," Decision Support Systems, vol. 54, no. 4, pp. 1580-1586, 2013.

[22] P. Liu, X. Qu, H. Yu, W. Wang, and B. Cao, "Development of a VISSIM simulation model for U-turns at unsignalized intersections," Journal of Transportation Engineering, vol. 138, no. 11, pp. 1333-1339, 2012.

[23] W. Dong, Y. Wang, and H. Yu, "An identification model of urban critical links with macroscopic fundamental diagram theory," Frontiers of Computer Science, vol. 11, no. 1, pp. 27-37, 2017.

[24] Q. Zhou and Z. Li, "Experimental analysis of various types of road intersections for interchange detection," Transactions in GIS, vol. 19, no. 1, pp. 19-41, 2015.

[25] Q. Li, "Integration of dynamic vehicle routing and microscopic traffic simulation," in Proceedings of the 7th International IEEE Conference on Intelligent Transportation Systems, ITSC '04, pp. 1023-1027, October 2004.

[26] Institute of Transportation Engineers, Trip Generation, Institute of Transportation Engineers, Washington, D.C., USA, 1997.

[27] K.-T. Chang, Z. Khatib, and Y. Ou, "Effects of zoning structure and network detail on traffic demand modeling," Environment and Planning B: Planning and Design, vol. 29, no. 1, pp. 37-52, 2002.

[28] N. Bakshi, S. E. Flynn, and N. Gans, "Estimating the operational impact of container inspections at international ports," Management Science, vol. 57, no. 1, pp. 1-20, 2011. 


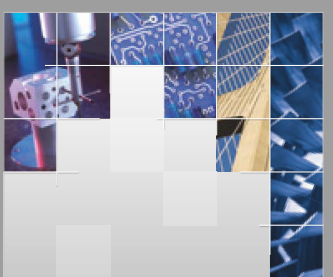

\section{Enfincering}
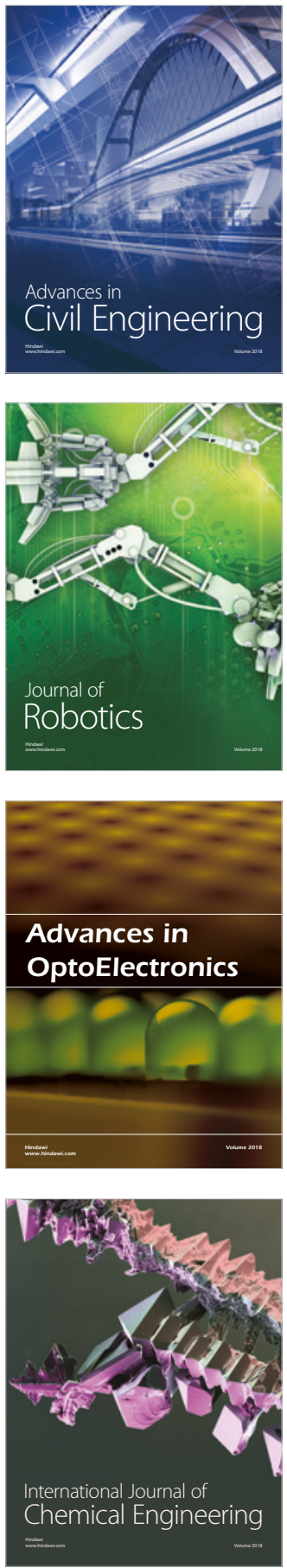

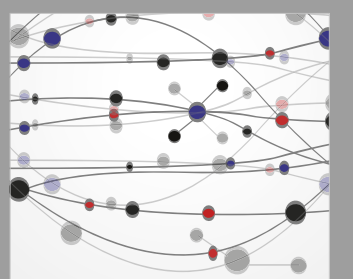

\section{Rotating \\ Machinery}

The Scientific World Journal

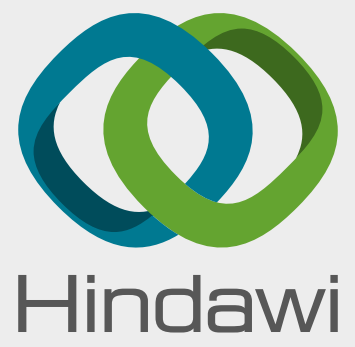

Submit your manuscripts at

www.hindawi.com
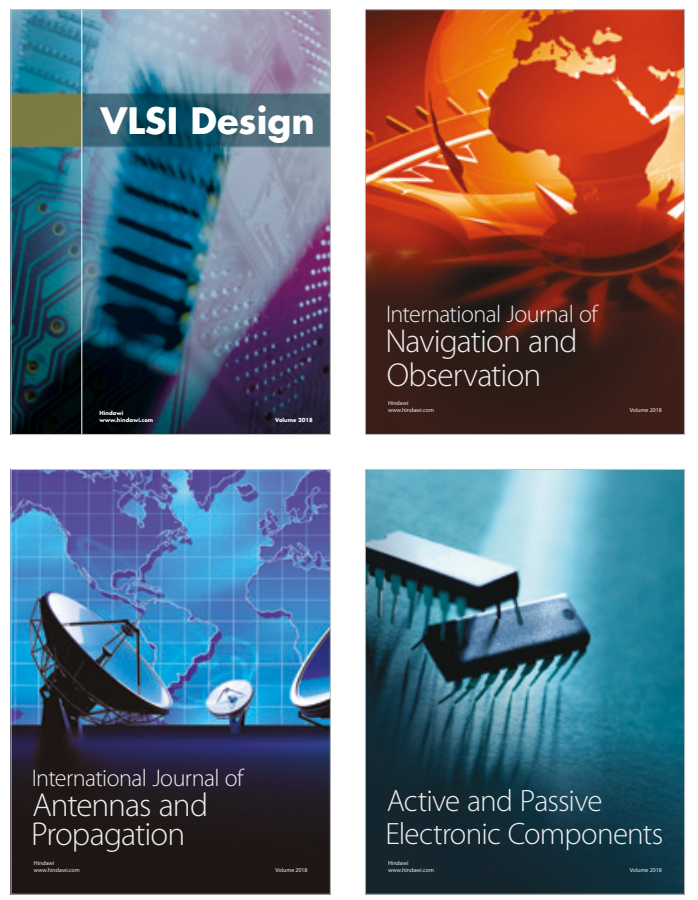
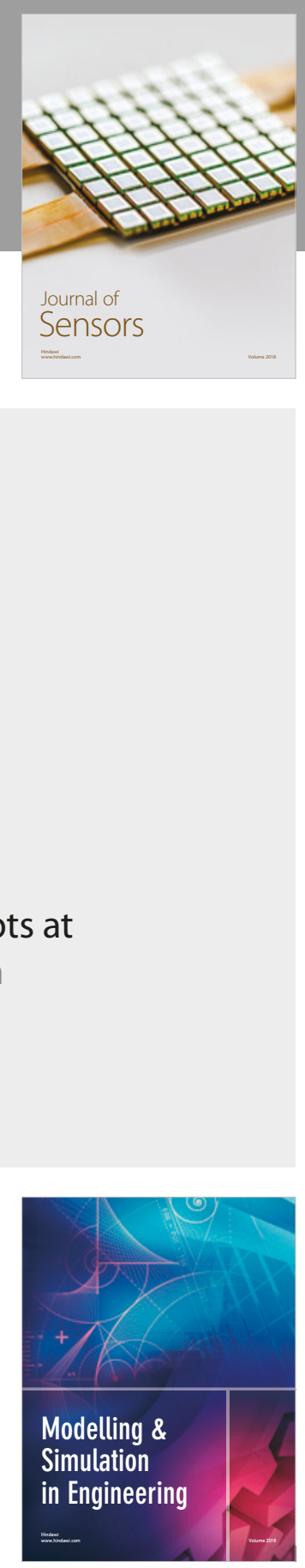

\section{Advances \\ Multimedia}
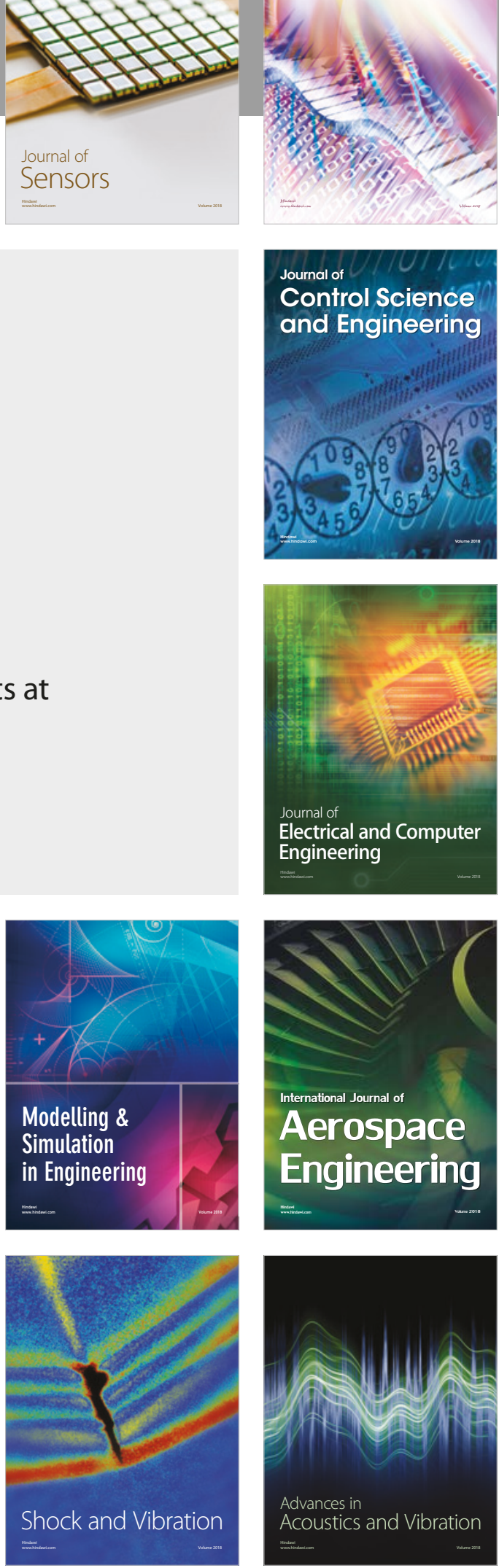